\title{
The Role of Trade in Structural Transformation
}

\author{
Marc Teignier \\ Universitat de Barcelona and BEAT. Diagonal 696, 08034 Barcelona, Spain. E-mail: marc.teignier@ub.edu. \\ September 14, 2017
}

\begin{abstract}
Low agriculture productivity is considered a key obstacle to economic development for many countries. International trade in agricultural goods can help overcome this barrier and facilitate structural transformation because it allows countries to import part of their food needs. This article quantifies the role of trade in this context through the examples of South Korea during the last 50 years and Great Britain in the 19th century. To do the analysis, I calibrate and simulate a two-sector, neoclassical growth model to match the data and perform the policy experiments. I find that agricultural imports played a crucial role in the early transformation of Great Britain, while, in South Korea, trade also had a positive impact on its structural transformation but it could have played a much larger role if the country had not introduced agricultural protection policies.
\end{abstract}

JEL classification numbers: O41, F11, Q18.

Keywords: sectoral reallocation, agricultural productivity, comparative advantage, agricultural trade policy. 


\section{Introduction}

The transition out-of-agriculture is a key aspect of economic development. When poor, countries allocate more than $80 \%$ of their workforce in agriculture and, as development takes place, this fraction keeps falling. In most rich countries, it is currently below 5\%. Low agricultural productivity is often considered responsible for these differences because it forces countries to keep enough resources in the agricultural sector to produce all their food needs. ${ }^{1}$ As this article shows, international trade can play a key role in this context by allowing countries to import part of their food consumption and thus accelerate their structural transformation .

The goal of this article is to evaluate the quantitative importance of this channel by analyzing two important episodes, namely the structural transformation of Great Britain during the 19th century and the one of South Korea during the last 50 years. The analysis of these two countries is interesting because they are fast-growing economies, very open to international trade and with a clear comparative advantage outside agriculture. ${ }^{2}$ At the same time, they both have some unique features. Great Britain was the first country to experience the industrial revolution and, as we can see in the first plot of Figure 1, its agricultural sector has been significantly smaller than elsewhere since 1800. South Korea, on the other hand, is the largest economy among the so-called East Asian growth miracles and it developed a competitive industrial sector very quickly. Its employment share in agriculture was about 65\% in 1960 and it is now less around 5\%, a fall that took the United States more than 150 years.

The importance of trade for the structural transformation of countries is sometimes disregarded in the literature because the actual trade flows in agricultural goods are often small, which is sometimes attributed to the presence of policy distortions, high transporta-

\footnotetext{
${ }^{1}$ See Schultz (1953), Caselli (2005), Gollin et al. (2007), Johnston and Mellor (1961), or Restuccia et al. (2008).

${ }^{2}$ In particular, Great Britain had a slightly larger income growth rate than the United States in the 19th century, while South Korea income per capita was around 10\% of the United States one in the 1960s and it is now more than $70 \%$. Net agricultural imports over agricultural GDP have been, on average, about $20 \%$ in the case of South Korea during the sample period and were about $80 \%$ in the case of Great Britain. Some of the main agricultural imports in South Korea, for the year 2010, were maize, wheat, sugar, meat, or soybeans; in Great Britain, for the year 1845, some of the main agricultural imports were sugar, corn, wine, or tea.
} 

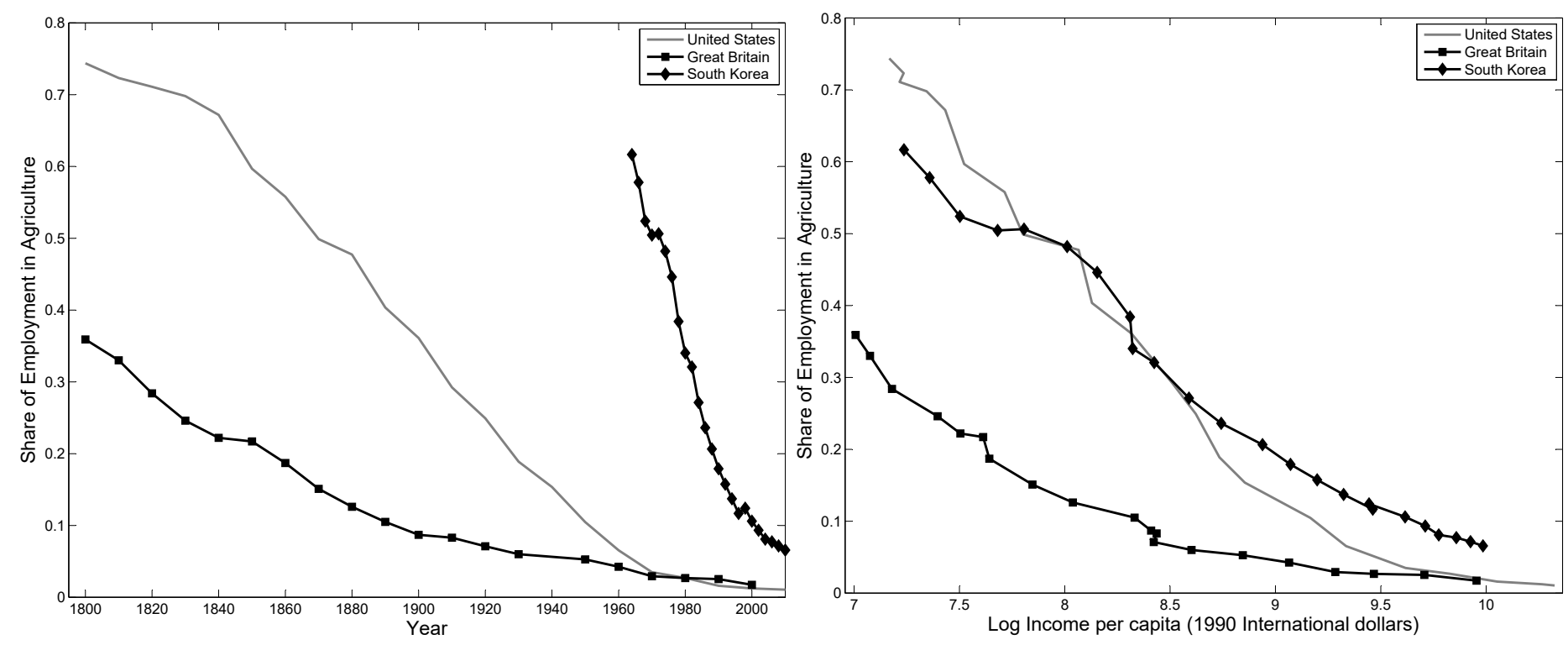

Figure 1: Structural transformation in Korea and Great Britain in comparison to the United States

tion costs, and the lack of adequate infrastructure in may developing countries. ${ }^{3}$ Gollin et al. (2007), for example, show that in the year 2000, only $14 \%$ of countries imported more than $15 \%$ of their total food grain consumption, while Tombe (2015) argues that the share of domestically produced goods in total expenditures is larger in agriculture due to larger trade costs like border delays. Moreover, once the level of income is taken into account, countries look fairly similar in terms of their agricultural sector size. ${ }^{4}$ As we can see in the second plot of Figure 1, somewhat surprisingly, this is also the case in South Korea, where the employment share in agriculture at each income level is actually extremely similar to the United States one. Interestingly, however, this is not the case in Great Britain, where the agricultural employment share during the last two centuries is less than half the United States one. In this article I show, first, that trade accounts for most of the difference between Great Britain and the United States and, second, that South Korea would have behaved like Great Britain had the country not adopted agricultural protection policies.

To do the analysis, I introduce international trade into a general equilibrium, neoclassical growth model with two sectors, agriculture and the rest of the economy. In the model,

\footnotetext{
${ }^{3}$ See, for instance, Adamopoulos (2011).

${ }^{4}$ See, for example, Herrendorf et al. (2014).
} 
preferences are non-homothetic, which makes consumers spend a large fraction of their income in the agricultural good when they are poor. Consequently, under autarky, low income countries allocate most of its productive resources to agriculture. As technological change occurs and capital accumulates, consumers get richer and their nonagricultural consumption share increases. Productive resources are then reallocated from the agricultural sector to the nonagricultural one, i.e. structural transformation takes place. Moreover, since the goods are complements, a fall in the agricultural good relative price also leads to structural transformation. Under international trade, on the other hand, the production pattern depends on the world prices and, hence, it may be different than the consumption pattern. In particular, when the domestic relative price of the agricultural good under autarky is higher than the international one, countries import agricultural good and reduce their agricultural production. Their transition-out-of agriculture, as a result, accelerate.

The model is calibrated to match the structural transformation of Great Britain in the 19th century and South Korea in the period 1963-2015. It is then used to perform the policy experiments that allow us to evaluate the importance of international trade in this process. The results show that, in the case of Great Britain, international trade was extremely important to explain its early structural transformation and it led to large welfare gains. Specifically, if the country had been in autarky, its agricultural employment share at the beginning of the 19th century would have been almost $80 \%$, more than two times the actual one and as large as the United States one. Trade led to faster capital accumulation and higher consumption of both goods over most of the period, which implied faster real income growth and higher intertemporal welfare. The average real income growth rate, which was $1.5 \%$ in the baseline simulation, would have been $0.9 \%$ under autarky, while the welfare gains with respect to the autarky scenario are equivalent to an increase in the yearly consumption expenditures of $5.3 \%$.

In South Korea, international trade also played a positive role in its structural transformation, although smaller than in Great Britain. Agricultural imports allowed South Korea to have a smaller agricultural sector - about three fourths of the autarky size - and expe- 
rience a real income growth of $5.6 \%$ instead of $5.2 \%$. All in all, it implied a welfare gain equivalent to a $0.4 \%$ increase in the yearly consumption expenditures under autarky. However, if the country had not adopted policies to protect its agricultural sector from foreign competition, the volume of trade would have been much larger and the country would have experienced an even faster transformation. The agricultural employment share at each income level would have been very similar to the one in Great Britain, and it would have dropped below $10 \% 25$ years earlier than it did. Its real income growth would have been much higher than the autarky one - $-7.1 \%$ instead of $5.2 \%$ - and the intertemporal gain with respect to autarky would have been equivalent to an increase in the autarky annual consumption expenditures of $8.8 \%$. These results are quite robust to changes in the value of the preference or production parameters, as well as to extending the model to include manufactures and services on top of agriculture.

There is a large body of literature examining the structural transformation of countries. ${ }^{5}$ Initially, most of the articles studied this phenomenon in a closed economy context, but there is now an emerging literature doing it from an open economy perspective. ${ }^{6}$ One of the first open-economy structural transformation articles was Matsuyama (1992), which was followed by others like Echevarria (2008), Matsuyama (2009), Dessy and Pallage (2010), and Deardorff and Park (2010). On the quantitative side, one of the first open economy articles is Stokey (2001), which considers international trade as one of the factors behind the English industrial revolution. One important difference with respect to my paper is that she quantifies the role of each factor assuming the economy is in a steady state in 1780 and in another one in 1850, instead of looking at the entire transition path.

More recently, other authors like Uy et al. (2013), Sposi (2012), or Betts et al. (2016), also examine the structural transformation of South Korea in an open economy context. Uy et al. (2013) find that the open economy version of their multi-sector Ricardian trade model fits

\footnotetext{
${ }^{5}$ See Herrendorf et al. (2014) for a comprehensive review.

${ }^{6}$ Some important closed-economy theoretical contributions are Echevarria (1997), Kongsamut et al. (2001), Ngai and Pissarides (2007), or Acemoglu and Guerrieri (2008). Some important closed-economy quantitative contributions are Caselli and Coleman II (2001), Gollin et al. (2004), Gollin et al. (2007), Dennis and Iscan (2007), Hayashi and Prescott (2008), Restuccia et al. (2008), Buera and Kaboski (2009), Duarte and Restuccia (2010) Alvarez-Cuadrado and Poschke (2011)or Herrendorf et al. (2013).
} 
the South Korea employment shares evolution in the period 1971-2005 significantly better than the closed economy version. Sposi (2012) uses a dynamic multi-sector trade model to show that the evolution of of comparative advantage accounts for a large portion of the rise in manufacturing exports of South Korea between 1960 and 1995. Finally Betts et al. (2016) construct time-series data on export subsidies and tariff rates by sector for South Korea from 1963 to 2000 and introduce them into a multi-sector trade model to evaluate their effects on the structural transformation of the country. ${ }^{7}$

This paper has some crucial differences with respect to this set of articles studying the structural transformation of South Korea. First, I use a growth model with endogenous savings and capital accumulation, which is a key determinant of the speed of transformation, as well as an important driving force behind the evolution of the relative prices and of the sectoral composition. This is especially important when computing the effects of the policy experiments on economic growth and intertemporal welfare. Second, also in contrast to the aforementioned literature, I study and compare two different structural transformation episodes, namely Great Britain in the 19th century and South Korea more recently. From this comparison we learn that the two episodes are much more similar than initially thought and that the observed differences are mainly due to distinct trade policies. Finally, I use trade flow data on net agriculture imports time path for both South Korea and Great Britain to parametrize the model, which is not the case in other articles in the literature.

The rest of this article is organized as follows. Sections 2 describes the two-sector growth model, both for closed and open economies. Section 3 describes the model parametrization and shows its performance relative to the two structural transformation episodes. Section 4 presents the policy experiments aimed at quantifying the role of international trade in the structural transformations of South Korea and Great Britain, while Section 5 shows the sensitivity of the main results to different preference specifications. Finally, Section 6 concludes. The details of the model analysis as well as the exogenous variables data sources

\footnotetext{
${ }^{7}$ Other recent articles analyzing quantitatively the gains from trade in models of structural change are Stefanski (2014), Tombe (2015), Sposi (2016), or Święcki (2017). Connolly and Yi (2015), on the other hand, use a neo-classical growth model with trade together with data from Korea between 1962 and 1995 to analyze the effects of tariff reductions on manufacturing productivity.
} 
are available in the Appendix.

\section{A Model of Structural Transformation}

\subsection{Model Setup}

In this section, I present and analyze the two-sector growth model, first its closed economy version and second its small open economy version. It is similar to the model in Hayashi and Prescott (2008) and it is also related to other two-sector growth models in the literature like Echevarria (1997) or Gollin et al. (2007). In my model, one of the sectors in the economy is agriculture, which produces a good that is only used for consumption. The other is the nonagricultural sector, which produces a good that is used for consumption as well as investment.

Household's description. In the model, there is a representative household with $N(t)$ infinitely-lived members, who derive utility from consuming the two goods:

$$
\begin{aligned}
U(0) & =\int_{0}^{\infty} e^{-(\rho-\nu) t} \log (\tilde{c}) d t, \text { where } \\
\tilde{c} & =\left[\omega^{\frac{1}{\epsilon}}\left(c_{1}-\overline{c_{1}}\right)^{\frac{\varepsilon-1}{\varepsilon}}+\left(c_{2}\right)^{\frac{\varepsilon-1}{\varepsilon}}\right]^{\frac{\varepsilon}{\varepsilon-1}}, \varepsilon \in[0, \infty) .
\end{aligned}
$$

The variables $c_{1}$ and $c_{2}$ denote the amount of agricultural and nonagricultural good, respectively, consumed by each household member. The parameter $\varepsilon$ would be the elasticity of substitution between the two consumption goods if $\overline{c_{1}}$ was zero, $\rho$ is the intertemporal discount factor, and $\nu$ is population growth. The parameter $\overline{c_{1}}$ makes the preferences nonhomothetic, in the sense that when income increases the agricultural good expenditure share falls. It can be interpreted as the agricultural good subsistence consumption level.

Households own the stocks of capital and land, which they supply to firms together with their labor endowment. At each period, household choose their consumption of both goods and their savings, as well as the sector at which they rent the inputs they own. In the model, inputs are perfectly mobile across sector, which implies that there is a unique wage 
rate $w$, capital rental rate $R$, and land rental rate $p$. The period-by-period household budget constraint, expressed in per capita terms, is given by

$$
\frac{d k}{d t}=w+(R-\delta-\nu) k+p\left(\frac{L}{N}\right)-q c_{1}-c_{2},
$$

where the price of the nonagricultural good is normalized to $1, q$ denotes the relative agricultural good price, $L / N$ the stock of land per capita, and $\delta$ the capital depreciation rate. All the variables are time functions except for the parameter $\delta$ and the land stock $L$, which are constant over time.

The optimization problem of a representative household consists on choosing $\left[c_{1}(t)\right.$, $\left.c_{2}(t), k(t)\right]_{t \geq 0}$ to maximize Equation (2) subject to Equation (3), and given an initial $k_{0}$.

Firms' description. In the model, there are also many identical firms in each sector. The production function for the nonagricultural good is given by

$$
y_{2}=\left(k_{2}\right)^{\alpha}\left(A_{2} n_{2}\right)^{1-\alpha},
$$

where $y_{2}$ denotes per-capita nonagricultural output, $A_{2}$ the nonagricultural total factor productivity, $k_{2}$ the nonagricultural stock of capital per capita, and $n_{2}$ the employment share in nonagriculture. Similarly, the agricultural good production function is given by

$$
y_{1}=\left(k_{1}\right)^{\eta}\left(A_{1} n_{1}\right)^{\beta}\left(\frac{L}{N}\right)^{1-\eta-\beta},
$$

where $y_{1}$ denotes per-capita agricultural output, $A_{1}$ the agricultural total factor productivity, $k_{1}$ the agricultural stock of capital per capita, and $n_{1}$ the employment share in agriculture. The per-capita land stock, $L / N$, falls over time because the stock of land is fixed and population growth is positive. Total factor productivity grows exogenously in both sector at (potentially different) rates $\gamma_{2}$ and $\gamma_{1}$, which are defined as

$$
\gamma_{2} \equiv \frac{d A_{2} / d t}{A_{2}}, \gamma_{1} \equiv \frac{d A_{1} / d t}{A_{1}}
$$


The optimization problem of firms consists on choosing the amount of labor and capital to hire in order to maximize their profits. Since firms exhibit constant returns to scale and there is perfect competition, the total number of firms is irrelevant for the equilibrium and, therefore, we can solve for the competitive equilibrium as if there was a representative firm in each sector.

\subsection{Closed Economy Competitive Equilibrium}

A competitive equilibrium for the closed economy, given the initial capital stock $k_{0}$ and the exogenous variables $\left[A_{1}(t), A_{2}(t), N(t)\right]_{t \geq 0}$, are a set of prices $[w(t), R(t), q(t), p(t)]_{t \geq 0}$ and quantities $\left[y_{1}(t), y_{2}(t), c_{1}(t), c_{2}(t), n_{1}(t), n_{2}(t), k_{1}(t), k_{2}(t), k(t)\right]_{t \geq 0}$ which satisfy the consumer optimization conditions, the firm optimization conditions, and the market clearing conditions (which guarantee that the amount of goods and inputs supplied domestically is equal to the amount demanded domestically). Appendix A contains a detailed description of the closed economy equilibrium conditions.

In terms of the long-run equilibrium, if the two consumption goods are complements in the households' preferences, i.e. $\varepsilon<1$, there is positive TFP growth in both sectors, i.e. $\gamma_{1}>0$ and $\gamma_{2}>0$, and the following condition is satisfied

$$
(1-\eta) \gamma_{2}+(1-\eta-\beta) \nu-\beta \gamma_{1}<0,
$$

then the economy converges to an asymptotic steady state where all the inputs are allocated in the nonagricultural sector. Equation (7) states that agricultural TFP growth must be large enough relative to the nonagricultural one to compensate for the fact that land per capita falls with population growth. These conditions guarantee that agricultural consumption increases over time, implying that the non-homothetic term $\underline{c_{1}}$ becomes less and less important over time and, in the limit, making the economy behave as if the term $\tilde{c}$ in Equation (2) was $\tilde{c}=\left[\omega^{\frac{1}{\epsilon}}\left(c_{1}\right)^{\frac{\varepsilon-1}{\varepsilon}}+\left(c_{2}\right)^{\frac{\varepsilon-1}{\varepsilon}}\right]^{\frac{\varepsilon}{\varepsilon-1}}$.

Structural Transformation in a Closed Economy. During the transition, there are two 
forces leading to structural transformation, one of them being changes in income and the other one being changes in relative prices. As households' get richer, their consumption expenditure share in agricultural good decreases because preferences are non-homothetic and the agricultural good has the lower income elasticity. This is known as the income effect, which would not exist if $\underline{c_{1}}=0$. At the same time, whenever $\varepsilon \neq 1$, the sectoral reallocation in an economy are also affected by changes in the relative price $q$. In the case of $\varepsilon<1$ (when the two goods are complements), the relative price effect also makes the agricultural sector shrink whenever the relative price of the agricultural good falls. In this framework, the evolution of this relative price is not only determined by the sectoral TFP growth rates, but it also affected by population growth (because it affects negatively the stock of land per capita available) as well as capital deepening (whenever $\alpha \neq \eta$ ) and the sectoral composition (as long as $\alpha \neq \eta$ and $\eta+\beta<1$ ).

\subsection{Small Open Economy Competitive Equilibrium}

The small open economy equilibrium is almost identical to the closed economy one except for the fact that the agricultural good relative price, $q$, is now exogenous to the country (since it is set in the international markets) and the fact that the country can import and export both goods (with $x_{1}$ and $x_{2}$ denoting agricultural and nonagricultural net exports respectively). Formally, a competitive equilibrium for the small open economy, given the initial capital stock $k_{0}$ and the exogenous variables $\left[A_{1}(t), A_{2}(t), q(t), N(t)\right]_{t \geq 0}$, are a set of prices $[w(t), R(t), p(t)]_{t \geq 0}$ and quantities $\left[y_{1}(t), y_{2}(t), c_{1}(t), c_{2}(t), x_{1}(t), x_{2}(t), n_{1}(t), n_{2}(t)\right.$, $\left.k_{1}(t), k_{2}(t), k(t)\right]_{t \geq 0}$, satisfying the consumer optimization conditions, the firm optimization conditions and the market clearing conditions. In this case, the market clearing conditions state that the amount of inputs supplied domestically is equal to the amount demanded domestically, and that the domestic demand of final goods plus net exports are equal to the domestic supply. International trade is assumed to be balanced at all periods, which implies that there is not international lending or borrowing. Appendix A also contains a detailed description of the equilibrium conditions as well the equilibrium dynamics in the 
small open economy model.

In terms of the long-run equilibrium, in a context where the international price of the agricultural good decreases over time, the economy converges to an asymptotic steady state where all inputs are allocated in the nonagricultural sector provided that the following condition is satisfied:

$$
(1-\eta) \gamma_{2}+(1-\eta-\beta) \nu-\beta \gamma_{1}>\gamma_{q}
$$

where $\gamma_{q} \equiv \frac{d q}{d t}$. In words, the economy converges to a nonagricultural steady state if the international price of the agricultural good falls at a faster rate than the rate that would prevail asymptotically in a closed economy context.

Structural Transformation of a Small Open Economy. Along the transition path, the sectoral composition depends on the relation between the domestic and the international price of the agricultural good, but not on the household's preferences. Because land can only be used in agriculture, both goods will be produced unless the economy specializes in agriculture because its international relative prices is high enough. Countries with low agricultural productivity or low land endowment will tend to import agricultural good and, hence, their agricultural sector will be smaller under trade than under autarky. Over time, assuming that $\gamma_{q}<0$ and equation (8) is satisfied, the economy will keep reallocating its inputs away from agriculture and, thus, structural transformation will take place. ${ }^{8}$

\section{Model Simulations}

In this section, I parametrize and simulate the small open economy model presented in Section 2.3 in order to match the agricultural employment share and the net agricultural imports of Great Britain in the 19th century and South Korea during the period 1963-2015. ${ }^{9}$

\footnotetext{
${ }^{8}$ To understand the relationship between trade and structural transformation better, it may be useful to look at a simplified version of the model where $\varepsilon=1$ and $\alpha=\eta=0$. In that version of the model, the employment share in agriculture would be $n_{1}=\frac{\omega \beta}{1+\omega \beta}+\frac{1}{1+\omega \beta} \frac{c_{1}}{y_{1} / n_{1}}+\frac{x_{1}}{y_{1} / n_{1}}$, which depends negatively on the volume of net agricultural imports, $-x_{1}$. Agricultural imports depend negatively on the international price of the agricultural good, which implies that the agricultural employment share depends positively on that price.

${ }^{9}$ During the period studied, Great Britain controlled a vast empire with large trade flows between the
} 
To simulate the model, one must first specify the parameter values, as described in Section 3.1, and then the path of the exogenous variables both for the sample period and for future periods, as described in Section 3.2 for South Korea and 3.3 for Great Britain. All the exogenous variables are smoothed with a constant trend, with no attempt to account for short-run fluctuations. Appendices B.1 and B.2 contain a detailed description of these exogenous variables as well as their data sources.

Note that the small open economy assumption implies that the relative price faced by a country is set in the international markets and, hence, it is not affected by changes in a country's demand or supply. This assumption is completely innocuous for the baseline simulations of Sections 3.2 and 3.3, since the relative price is directly taken from the data. It does not matter either for the results of the autarky counterfactuals in Section 4, because countries closed to international trade are not affected by them and, hence, it does not matter whether they react or not. The small open economy assumption does matter, however, for counterfactuals where countries change their tariffs and remain open to international trade. This is the case in the South Korea free trade counterfactual (Section 4.1), but the small open economy assumption seems reasonable for South Korea in the last 50 years. The same policy experiment would probably have been more controversial for Great Britain in the 19th century because it was a large economy in the international markets, but there is no such exercise in this article.

At the same time, the model also assumes that there is balanced trade at all points in time, which means that the value of imports is equal to the value of exports. The data shows that on average both countries had a small trade deficit during the sample period (about 3\% in the case of South Korea and about $6.4 \%$ in the case of Great Britain). As a result, the actual nonagricultural exports were lower than predicted by the model, while the actual nonagricultural consumption was higher than predicted by the model. The welfare

metropole and its colonies. It is not clear, however, that the observed trade patterns would change much without the restrictions imposed by the empire, as illustrated by the fact that trade with the 13 American colonies is not very different before and after their independence in 1776. Moreover, most of the net agricultural imports came from Continental Europe during the period studied ( $40 \%$ on average, compared to $6 \%$ from Ireland and $12 \%$ from the U.S.A. among others). 
benefits of trade obtained in Section 4, hence, would be slightly larger if the trade deficit was taken into account.

\subsection{Model Parametrization}

As we can see in Table 1, the model has four exogenous variables plus nine parameters: the production function parameters (that is, $\alpha, \eta, \beta$ ) introduced in Equations (4) and (5), the preference parameters (that is, $\rho, \omega, \varepsilon, \overline{c_{1}}$ ) from Equations (1) and (2), and, lastly, the depreciation rate $\delta$, shown in Equation (3).

The capital intensity parameter in the nonagricultural production function, $\alpha$, is set to $1 / 3$, which is the customary value used in the literature (see, for instance, Prescott (1986)). This implies a labor income share of $2 / 3$ in nonagriculture, which is exactly the average value in South Korea for the period 1963-1995 (see Kim and Hong (1997), page 79). With respect to the agricultural production function parameters, the capital intensity parameter, $\eta$, is set to 0.1 , while the labor intensity parameter, $\beta$, is set to 0.5 . These correspond, respectively, to the average capital and labor income shares in South Korea for the period 1963-1995 (see Kim and Hong (1997), page 67), and they are within the range of values used in the literature for other countries. They imply a land intensity of 0.4 , which is also in the range of values used in the literature for other countries. ${ }^{10}$

The values used for the capital depreciation rate, $\delta$, and the intertemporal discount factor, $\rho$, are 0.1 and 0.05 respectively, similar to the ones used in the literature (see Prescott (1986) or Cooley (1995)). Finally, the preference parameters, are chosen to minimize the distance between the net agricultural imports time path in the simulated model and in the data. The first two, $\omega$ and $\varepsilon$, take the same values in both countries, while $\overline{c_{1}}$ is estimated separately for each country because the data units are not directly comparable due to fact that even series in real terms are affected by the base-year prices, which differ across countries.

\footnotetext{
${ }^{10}$ Valentinyi and Herrendorf (2008) find that the labor income share in agriculture for the United States is 0.46 and the land income share is 0.18, while Hayashi and Prescott (2008) use 0.545 and 0.1932 for the case of Japan in the period 1885-1940, and Stokey (2001) uses 0.387 and 0.45 for the case of Great Britain between 1780 and 1850.
} 
Table 1: Parameter values and exogenous variables

\begin{tabular}{ccccc}
\hline & \multirow{2}{*}{ Description } & \multicolumn{2}{c}{ Values } & Source \\
& Korea & GB & Prescott (1986) \\
\hline$\delta$ & Capital depreciation rate & 0.10 & 0.10 & Prescott (1986) \\
$\rho$ & Intertemporal discount & 0.05 & 0.05 & Prescott (1986) \\
$\alpha$ & Nonagr. capital share & 0.33 & 0.33 & Korea Development Institute (1997) \\
$\eta$ & Agr. capital inc share & 0.10 & 0.10 & Korea Development Institute (1997) \\
$\beta$ & Agr labor inc share & 0.50 & 0.50 & To match net agricultural imports data in Korea. \\
\hline$\omega$ & Agr consumption rel weight & 0.025 & 0.025 & To match net agr. imports data in each country. \\
$\varepsilon$ & Elasticity of substitution & 0.050 & 0.050 & Own calculations. \\
\hline$c_{1}$ & Subsistence agr. cons. & $98 \%$ & $99 \%$ & Own calculations. \\
& (as \% initial agr. cons.) & & & Own calculations. \\
\hline$\gamma_{1}$ & Agr. sector TFP growth rate & $7.9 \%$ & $2.2 \%$ & Own calculations. \\
$\gamma_{2}$ & Nonagr. sector TFP growth rate & $4.3 \%$ & $1.7 \%$ & $1.2 \%$ \\
$\nu$ & Total population growth rate & $1.1 \%$ & $-0.1 \%$ & To match initial employment share in agriculture. \\
\hline$\gamma_{q}$ & Agr. relative price growth & $-1.4 \%$ & &
\end{tabular}

Since data on trade flows is available on a yearly basis for South Korea (and they may be considered more reliable because they are from the National Accounts), the parameters $(\omega, \varepsilon)$ are estimated using data on net agricultural imports in South Korea, but they provide a good fit for the British data as well (see Section 3.3). I find that the distance between the model predictions and the South Korean net agricultural imports is minimized when the parameter $\varepsilon$ takes a value of $0.05, \omega$ takes a value of 0.025 , and $\overline{c_{1}}$ is equal to $98 \%$ of the initial agricultural consumption. ${ }^{11}$ For Great Britain, I find that the model performance is maximized when $\overline{c_{1}}$ is equal to $99 \%$ of the initial agricultural consumption.

\subsection{Analysis of South Korea Transformation}

South Korea exogenous variables. There are four exogenous variables that need to be specified for the small open economy simulations, namely total population, agricultural

\footnotetext{
${ }^{11}$ For comparison purposes, Herrendorf et al. (2013) use $\omega=0.001$ and $\varepsilon=0.06$, while Uy et al. (2013) use $\omega=0.131$ and $\varepsilon=0.751$. Others likeCaselli and Coleman II (2001), Hayashi and Prescott (2008), or Duarte and Restuccia (2010) assume the utility function is of Cobb-Douglas type, which implies $\varepsilon=1$. Caselli and Coleman II (2001) and Duarte and Restuccia (2010) use $\omega=0.01$, while Hayashi and Prescott (2008) use $\omega=0.176$.
} 
TFP and nonagricultural TFP, as well as the agricultural good relative price. All of them are smoothed imposing a constant growth rate, as shown in Appendix B.1. Table 1 shows the growth rates of the exogenous variables, together with the parameter values for the baseline simulations.

Total population growth is computed directly from the data, and its average growth rate is estimated to be $1.13 \%$. The relative price of the agricultural good is computed as the agricultural GDP deflator over the nonagricultural GDP deflator, and its average growth rate is $-1.39 \%$. TFP at the sector level is constructed using data on real GDP as well as employment shares by sector and data on the aggregate capital stock, assuming that the capital stock is efficiently allocated across sectors. The agricultural sector corresponds to Agriculture, Forestry and Fishing in the data, while the nonagricultural sector corresponds to the rest of the economy. In the case of the agricultural sector, the average TFP growth rate obtained is $7.91 \%$, while in the nonagricultural sector it is $4.33 \%$. The values used for the future are $6.71 \%$ and $3.13 \%$ respectively, and they are obtained assuming that the overall employment-to-population ratio will stop growing in 10 years. The initial value of the capital stock is taken directly from the data.

We also have to specify the initial value of the relative price, since its units in the data depend on the base year prices and, therefore, they do not have a direct translation into the model. ${ }^{12}$ In these simulations, the initial value of the relative price is chosen to match the initial employment share in the agricultural sector.

South Korea baseline simulation. As we can see in Figure 2, the simulated model for South Korea makes a good job in replicating the actual data for the agricultural employment share and the net agricultural imports during the period 1963-2007. Note that in terms of the agricultural employment share the initial value is matched thanks to the initial relative price $q_{0}$ but no parameter is chosen to optimize the model fit thereafter. With respect to the

\footnotetext{
${ }^{12}$ Mathematically, if we denote the agricultural good price by $p_{a}$ and the nonagricultural good price by $p_{n}$, the agricultural good price measure obtained from the data is $\frac{p_{a}(t) Y_{a}(t)}{p_{a}^{0} Y_{a}(t)}$ and the nonagricultural good price measure is $\frac{p_{n}(t) Y_{n}(t)}{p_{n}^{0} Y_{n}(t)}$, where $p_{a}^{0}$ and $p_{n}^{0}$ denotes the base-year prices of the national accounts. As a result, the relative price of the agricultural computed from the data is $\left(\frac{p_{a}(t) Y_{a}(t)}{p_{a}^{0} Y_{a}(t)}\right) /\left(\frac{p_{n}(t) Y_{n}(t)}{p_{n}^{0} Y_{n}(t)}\right)=\frac{p_{a}(t)}{p_{n}(t)} \frac{p_{n}^{0}}{p_{a}^{0}}$.
} 
Figure 2: South Korea baseline simulation
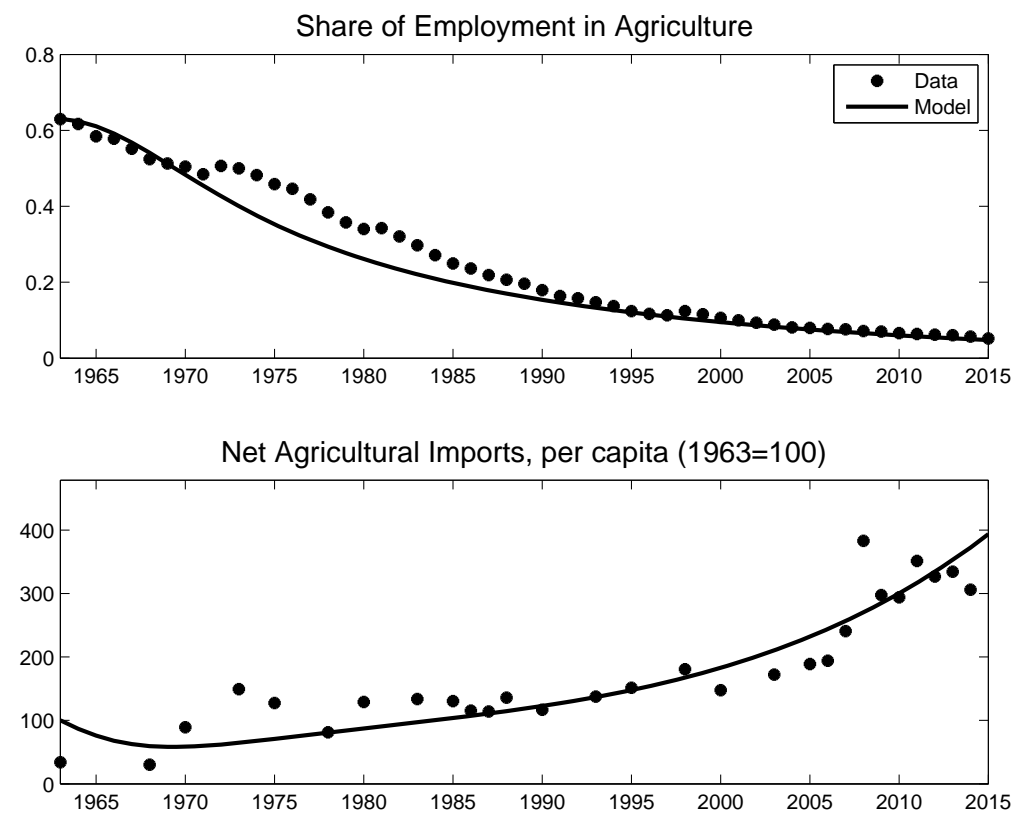

net agricultural imports data, the model parameters $\left(\omega, \varepsilon, \underline{c_{1}}\right)$ are set to optimize the fit of the model during the entire sample period.

\subsection{Analysis of Great Britain Transformation}

Great Britain exogenous variables. The procedure followed to obtain the Great Britain exogenous variables and generate the baseline simulation is exactly the same as in the case of South Korea. As we can in see in the fourth column of Table 1, the average population growth during the 19 th century is $1.24 \%$, while the average growth rate of the agriculturenonagriculture ratio of GDP deflators is $-0.065 \%$. The agricultural TFP average growth rate is $2.18 \%$, while it is $1.71 \%$ in the case of the nonagricultural TFP. The value used for the agricultural TFP growth rate is adjusted for future periods to $3.59 \%$ in order to guarantee that the conditions specified in equations (7) and (8) are satisfied. ${ }^{13}$

Great Britain baseline simulation. Figure 3 shows the model predictions for the employment share in agriculture and the net agricultural imports closely follow the actual

\footnotetext{
${ }^{13}$ The period studied here is the 19th century for data availability reasons, given that the sources used in this article, which were also used in Stokey (2001), do not go beyond 1900 for many series. In any case, the agricultural employment share was already below $10 \%$ at that time, so most of the structural transformation in the country had already taken place.
} 
Figure 3: Great Britain baseline simulation

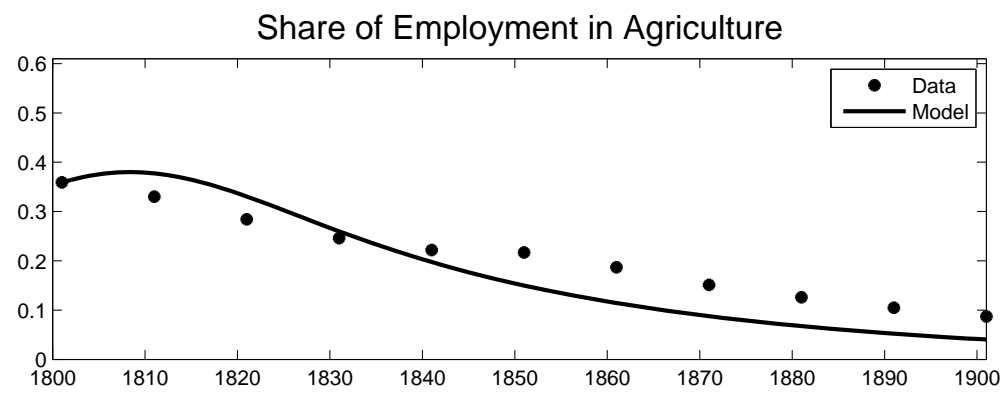

Net Agricultural Imports, per capita $(1800=100)$

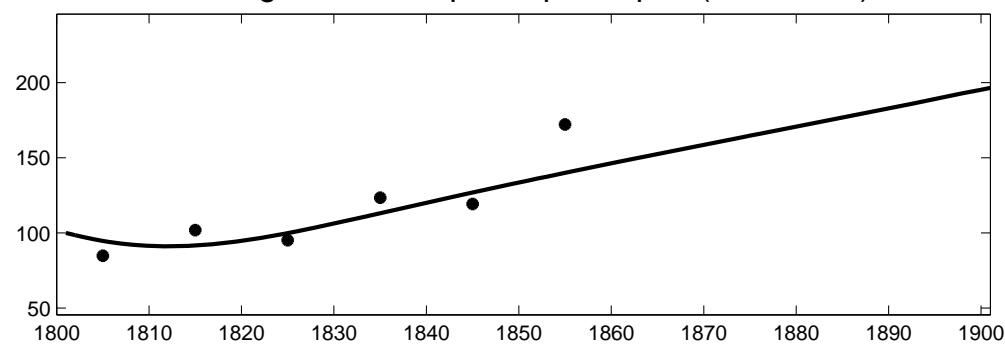

data. The fit of the baseline simulation is not as good as in the case of South Korea, since it slightly overpredicts the fall of the agricultural employment share. ${ }^{14}$

\section{Policy Experiments: Effects of International Trade}

In this section, I present the results of the counterfactual experiments performed to evaluate the importance of international trade in the structural transformations of South Korea (Section 4.1) and Great Britain (Section 4.2). Then, in section 4.3, I summarize and compare the main results of these experiments and I discuss their implications for economic growth and intertemporal welfare.

When analyzing the results below, it is important to keep in mind that this framework assumes frictionless mobility of production inputs and exogenous TFP growth at the sector level. If there were large frictions, the reallocation of capital and labor would be slowed down and the trade shock needed to explain the observed import patterns might be larger. Still, it is not clear that the effects of international trade with respect to the autarky equi-

\footnotetext{
${ }^{14}$ The agricultural trade data used here is not available after 1855. Moreover, trade with Ireland is not reported after 1825 and I estimate it assuming its share in the net agricultural imports total is the same as in the years $1800-1825$ (which is equal to $6.5 \%$ ).
} 
librium would be smaller. At the same time, if there were multiple industries within each sector, trade would also have an effect on the sectoral TFP by altering the sub-sectoral composition of the economy. In particular, if intrasectoral trade expanded the industries with higher productivity, trade could also raise TFP and, as a result, its positive effects on real income and welfare would be reinforced.

\subsection{The Role of Trade in South Korea}

In the case of South Korea, two policy experiments are performed. The first one consists on simulating the model under the autarky scenario, while the second one consists on simulating the model under the free trade scenario where all the policy distortions aimed at protecting the agricultural sector are removed.. These agricultural policies were likely to mitigate the effect of trade and, thus, the purpose of this second counterfactual is to predict the Korean transformation if they had not been adopted.

The autarky counterfactual simulates the model presented in Section 2.2 keeping all the parameters and exogenous variables as in the baseline simulation but eliminating all trade flows. If South Korea had to produce all its agricultural consumption, the relative price of the agricultural good would increase, leading to a rise of the agricultural employment share and agricultural production. As the first plot in Figure 4 shows, around $80 \%$ of the South Korean labor force would have been allocated to agriculture at the beginning of the sample period and around $10 \%$ at the end of the sample period.

The free trade counterfactual, on the other hand, simulates the model from Section 2.3 keeping all the parameters and exogenous variables as in the baseline simulation but adjusting the agricultural good relative price to remove the effect of the agricultural protection policies. There are many studies documenting the efforts of the Korean government to protect the agricultural sector from foreign competition and to increase the agricultural producers' income. ${ }^{15}$ I use the USDA report 'Structural change and agricultural protection: costs of Korean agricultural policy' (see Diao et al. (2002)), which estimates an agricultural sector tariff

\footnotetext{
${ }^{15}$ See, for example, the OECD Report 'Agricultural Policies at a Glance'.
} 
equivalent rate of 104\% in 1990 due not only to the explicit import tariffs and production subsidies but also to the quantitative restrictions such as direct government bans and quotas. The relative price that would have prevailed in South Korea under this counterfactual is then computed by removing the agricultural sector tariff equivalent rate for the year 1990 and assuming that its average growth rate would have been the same as the United States one, which is equal to $-2.63 \%$ during that period. ${ }^{16}$ The underlying assumption is that the United States is a big player in the international agricultural market and, hence, in the absence of policy distortions, the relative agricultural good price in South Korea would have evolved in the same way. ${ }^{17}$ As we can see in the second plot of Figure 4, not surprisingly, the share of employment in the agricultural sector would have been significantly smaller for the whole sample period. In particular, its initial level would have been $28 \%$ instead of 63\%, and it would have dropped below 10\% in 1974 instead of 1999.

\subsection{The Role of Trade in Great Britain}

In the case of Great Britain, the only counterfactual experiment performed is to simulate the model under autarky, which is then used to measure the role of trade in the country's structural transformation. Admittedly, some agricultural protectionist policies might have been present at the time, which means we may not want to interpret the baseline simulation as complete free trade. An important example are the Corn Laws, enacted from 1815 to 1846 to limit the entry of foreign wheat when its domestic price was considered too low. ${ }^{18}$ Without these policies, the country would have had even more agricultural imports and less agricultural employment during those years. The difference between a frictionless benchmark and the autarky counterfactual, thus, would be somewhat larger than the results presented

\footnotetext{
${ }^{16}$ Interestingly, this growth rate is almost identical to the one obtained using also the 1975 agricultural sector tariff equivalent rate estimated in Diao et al. (2002), which is $65 \%$.

${ }^{17}$ The United States has been the main source of South Korea's agricultural imports since 1955, when U.S. grain exports started as grants (see https://www.ers.usda.gov/topics/international-marketstrade/countries-regions/south-korea/trade/). According to the FAO data on agricultural trade flows, net agricultural imports from the U.S. were above 35\% of all the net agricultural imports in 1990 and are still above $20 \%$.

${ }^{18}$ According to Ward (2004), without the Corn Laws wheat prices would have been about $9 \%$ lower during these years.
} 
Figure 4: Effects of international trade on agricultural sector size
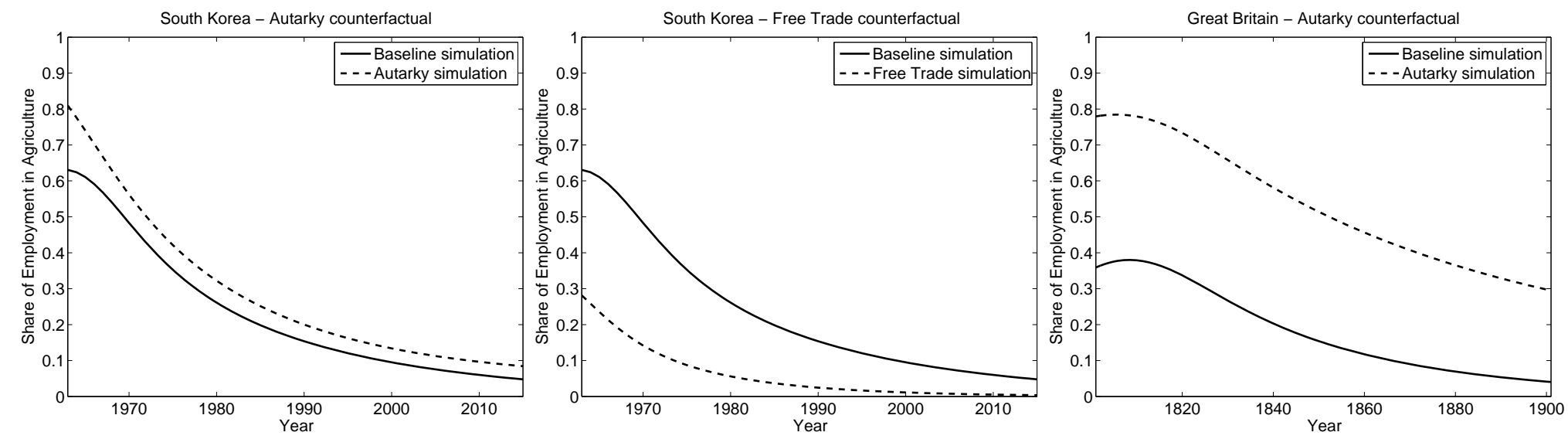

here, suggesting a slightly stronger role of international trade.

As before, the autarky counterfactual simulates the model in Section 2.2 keeping all the parameters and exogenous variables as in the baseline simulation but eliminating all the trade flows. The third plot in Figure 4 shows that had Great Britain been closed to international trade, its agricultural employment share would have more than doubled. As one would expect, if the country had not been able to import agricultural good from abroad, the relative price would have increased to make domestic supply equal to domestic demand, leading to an increase of domestic supply and a slight decrease of domestic demand with respect to the open economy scenario.

\subsection{Results Comparison and Effects on Income Growth and Welfare}

Effects on the Main Variables. The main effects of international trade on the episodes studied are summarized in Table 2 and Figure 5. As we can see in Table 2, in the case of South Korea (rows 1 and 2), the agricultural relative price has been about one tenth lower than it would have been under autarky, but it would have been less than half under free trade. As a consequence, the agricultural employment has been about three quarters of the one under autarky, but under free trade it would have have been less than one fifth of the autarky one. In the case of Great Britain (third row), the agricultural relative price was about two thirds the one it would have prevailed under autarky, while the agricultural 
employment was about one third.

With respect to the consumption volumes, trade unambiguously raised agricultural consumption due to its positive effect on real income as well as its negative effect on the agricultural good relative price. It also increased nonagricultural consumption because the income effect was high enough. Specifically, in South Korea, I find that both the agricultural and the nonagricultural consumption were slightly larger thanks to trade but while they would have been $4 \%$ and $17 \%$ higher if trade had not been restricted. In Great Britain, the agricultural consumption was almost $1 \%$ higher than the autarky one during the sample period, while the nonagricultural one was $29 \%$ higher on average.

At the same time, trade increased capital accumulation in these two episodes, first, because of its positive income effect and, second, because of its positive effect on the return to savings. In the examples studied here, trade leads an expansion of the nonagricultural sector, which increases the aggregate marginal product of capital because the nonagricultural sector is more capital intensive than the agricultural one. According to my results, in South Korea, the capital stock has been on average $4 \%$ higher during the sample period due to international trade, and it would have been $20 \%$ higher on average under free trade. In Great Britain during the 19th century, on the other hand, the stock of capital was on average $30 \%$ higher thanks to international trade. These numbers show that in this context trade has important effects on capital accumulation and that it is important to allow for savings to be endogenously determined.

Agricultural Sector Size Comparisons. Figure 5 shows graphically how the second plot in Figure 1 would change under each policy experiment. As the first plot of Figure 5 shows, the agricultural sector size in South Korea at each income level would have been very similar to the one observed in Great Britain if it had not restricted the trade flows to protects its agricultural sector. ${ }^{19}$ Specifically, in the data, there is an average gap in agricultural employment of about -2 percentage points between South Korea and the United States and

\footnotetext{
${ }^{19}$ The income level under each counterfactual is computed by adjusting the income levels from the Maddison Project database with the income obtained in each simulation.
} 
about -26 percentage points between Great Britain and the United States. ${ }^{20}$ Under free trade, the gap between South Korea and the United States would have been -28pp, very similar to the gap between Great Britain and the United States. Under autarky, most of the difference between the United States and Great Britain would disappear, as the second plot of Figure 5 shows. More precisely, in the autarky counterfactuals, the agricultural employment gaps with respect to the United States becomes +3pp in the case of South Korea and -4pp in the case of Great Britain, implying that more than $80 \%$ of the gap between Great Britain and the United States would have not existed without the British agricultural imports. ${ }^{21}$

The remaining gap in agricultural employment among the three countries under autarky can be explained by agricultural productivity differences. In particular, using the framework presented in this article, I find that if the agricultural productivity in Great Britain had been $10.1 \%$ lower, the autarky average gap with respect to the United States during the sample period would become zero. In South Korea, in opposition, the autarky average gap with respect to the United States in the sample period would vanish if its agricultural productivity had been $17.5 \%$ higher.

Economic Growth Analysis. Computing the real income growth in a two-sector framework is not straightforward and there is not a unique way to do it. The results presented in the fifth column of Table 2 are calculated as the nominal GDP growth minus the relative price growth. Mathematically, the real income growth between period 1 and period $T$ is computed as

$$
R G D P g=\frac{1}{T}\left(\frac{q(T) y_{1}(T)+y_{2}(T)}{q(1) y_{1}(1)+y_{2}(1)}-1\right)-\frac{1}{T}\left(\frac{q(T)}{q(1)}-1\right) .
$$

Under equation (9), the South Korea baseline simulation gives an average growth rate of $5.56 \%$, instead of $5.22 \%$ under autarky (i.e. 1.07 times higher). The free trade simulation, on

\footnotetext{
${ }^{20}$ To compute the average agricultural employment gap with respect to the United States, I estimate the polynomial that best fits the employment series at each income level and compare them to the United States one.

${ }^{21}$ One can think as the United States as a benchmark closed economy because its net agricultural exports have been between $-5 \%$ and $5 \%$ of its agricultural output for most of the years studied.
} 
Figure 5: Results comparison: agricultural sector size under different counterfactuals
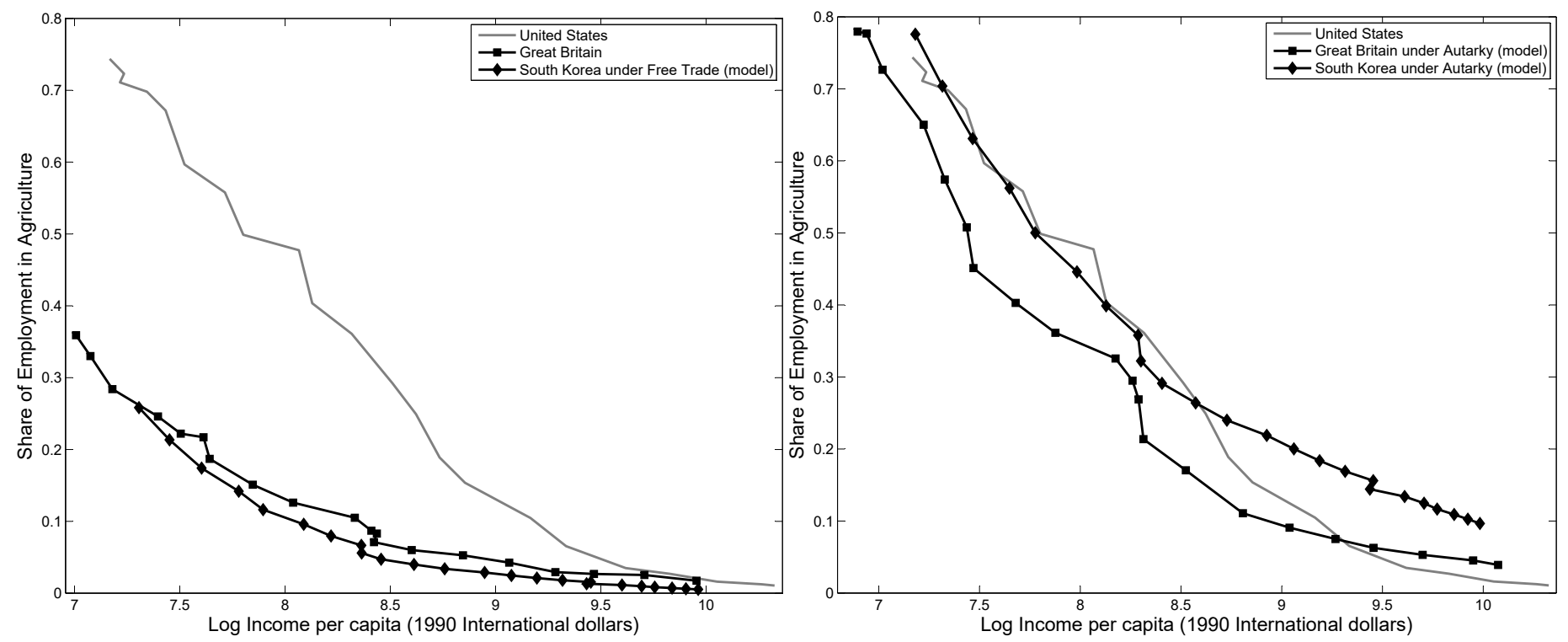

the other had gives an average growth rate of $7.13 \%$, which is almost 1.4 times higher than the closed economy one. Finally, in Great Britain, the average growth rate obtained under the baseline simulation is $1.47 \%$ and it would have been $0.91 \%$ under autarky, i.e. about 1.6 times higher.

Welfare Analysis. To measure the intertemporal welfare gain of the representative household due to trade, I compute the increase in the yearly consumption expenditures under autarky that delivers the same welfare gain, denoted by $\varphi$. Mathematically, if we define the autarky consumption expenditure as $m^{\text {aut }}(t) \equiv q^{\text {aut }}(t) c_{1}^{\text {aut }}(t)+c_{2}^{\text {aut }}(t)$ and the autarky intertemporal welfare as $U^{a u t} \equiv W\left(\left[m^{a u t}(t)\right]_{t \geq 0}\right)$, the measures $\varphi^{b}$ and $\varphi^{f t}$ are defined as

$$
W\left(\left[\left(1+\varphi^{b}\right) m^{a u t}(t)\right]_{t \geq 0}\right)=U^{\text {baseline }}
$$

and

$$
W\left(\left[\left(1+\varphi^{f t}\right) m^{\text {aut }}(t)\right]_{t \geq 0}\right)=U^{\text {free trade }},
$$

where $U^{\text {baseline }}$ denotes intertemporal under the baseline simulation and $U^{\text {free trade }}$ the intertemporal welfare under the free trade counterfactual.

The last column of Table 2 presents the results for the three policy experiments. I find 
Table 2: Results comparison: trade vs autarky

\begin{tabular}{|c|c|c|c|c|c|c|c|}
\hline $\begin{array}{l}\text { Ratio to autarky } \\
\text { simulation (sample } \\
\text { period average) }\end{array}$ & $\begin{array}{l}\text { Agr. Rel. } \\
\text { Price }\end{array}$ & Agr. Empl. & Agr. Cons. & $\begin{array}{l}\text { Nonagr. } \\
\text { Cons. }\end{array}$ & Capital & $\begin{array}{l}\text { Real GDP } \\
\text { Growth }\end{array}$ & $\begin{array}{l}\text { Welfare Gain } \\
\text { (cons. exp. } \triangle \text { ) }\end{array}$ \\
\hline $\begin{array}{l}\text { South Korea } \\
\text { - Baseline sim }\end{array}$ & 0.89 & 0.75 & 1.003 & 1.008 & 1.04 & 1.07 & $0.4 \%$ \\
\hline $\begin{array}{l}\text { South Korea } \\
\text { - Free trade sim }\end{array}$ & 0.45 & 0.14 & 1.04 & 1.17 & 1.20 & 1.37 & $8.9 \%$ \\
\hline $\begin{array}{l}\text { Great Britain } \\
\text { - Baseline sim }\end{array}$ & 0.61 & 0.31 & 1.009 & 1.29 & 1.30 & 1.61 & $5.3 \%$ \\
\hline
\end{tabular}

that in South Korea, the rise in intertemporal welfare relative to autarky is equivalent to the one obtained under a $0.4 \%$ increase of yearly consumption expenditures. In other words, the representative consumer of South Korea in 1963 is indifferent between opening up to international trade or remaining under autarky and increasing the consumption expenditures by $0.4 \%$ every year. If there had been no agricultural protection policies, the welfare gain in South Korea would have been equivalent to a $8.9 \%$ increase in the autarky annual consumption expenditures. In Great Britain, on the other hand, the intertemporal welfare gain due to international trade is equivalent to a $5.27 \%$ increase of the annual consumption expenditures, somewhat lower than the South Korea gains under free trade probably because the effects do not take place so fast. ${ }^{22}$

\section{Sensitivity Analysis}

The objective of this section is to present the main results under different model specifications and to show that the baseline simulation results are robust to them. The main results are presented in Table 3 , where columns 1 and 2 (for South Korea) and 9 and 10

\footnotetext{
${ }^{22}$ These gains in welfare obtained in this article are significantly larger than the ones predicted by the sufficient statistic in Arkolakis et al. (2012), who conclude that in a broad class of trade models the welfare gain is only a function of the import penetration ratio and the trade elasticity. The reason I obtain larger welfare gains could be that preferences are non-homothetic and capital accumulation rises or, simply, that the import penetration ratio falls over time.
} 
(for Great Britain) show the fit of the baseline simulations in terms of the agricultural employment share and the net agricultural imports. Column 3 is the real income growth rate relative to the autarky one for the South Korea baseline simulation, while column 6 is for the South Korea free trade simulation, and column 11 is for Great Britain baseline simulation. Columns 4, 7, and 12 display the increase in the autarky consumption expenditures equivalent to the welfare gain from international trade for the three counterfactuals. Finally, columns 5, 8, and 13 show the average gap of agricultural employment with respect to the United States under the three counterfactuals.

In terms of the preferences, the model is still able to replicate the data when $\varepsilon$ is set to $1 .^{23}$ These preferences are called Stone-Geary and they imply that changes in the relative prices do not affect the consumption shares. The model goodness of fit, however, would be much lower if the preferences were homothetic $\left(\overline{c_{1}}=0\right)$, implying that income effects are necessary to replicate the agricultural imports data for the periods analyzed. ${ }^{24}$ Comparing the first and second rows of Table 3 , we can see that setting $\varepsilon$ to 1 does not change the main results of the model significantly. Dennis and İşcan (2009) also find that the United States data until the 1950s can be explained by a model without price effects because the income effects are the main driver behind it.

In terms of the production function parameters, setting $\beta=2 / 3$ and, thus, equalizing the labor income shares in both sectors does not harm the ability of the model to fit the data. This would not be the case, however, if the capital income share were also equalized, since then the agricultural sector would also exhibit constant returns to scale and the model would then predict full specialization of countries under trade. Comparing the first and third rows of Table 3, we observe that equalizing the labor income shares across the two sectors does not change the results dramatically, although it increases the estimated effects

\footnotetext{
${ }^{23}$ Appendix C.1 contains the model analysis under these preferences.

${ }^{24}$ Intuitively, under $\overline{c_{1}}=0$, a low $\varepsilon$ is not enough to obtain a decent fit to the data and it is necessary to use a much higher value for $\omega$ in order to match the sample period net agricultural imports. This makes the model predict positive agricultural exports for the initial part of the sample and overpredict the importance of agricultural imports for the final periods. Note that this does not effect the employment allocation in the baseline simulation because it depends on the international price of the agricultural good and not on the domestic demand.
} 
of free trade in South Korea in terms of agricultural employment share and intertemporal welfare gains, while it reduces the effects of trade in Great Britain. Intuitively, a given price change now has stronger effects because the Production-Possibility Frontier of the economy is less curved but, for the same reason, a lower price change is necessary to explain the observed trade flows.

Finally, the last row of Table 3 presents the results when the model is extended to three sectors, namely agriculture, manufactures, and services. A detailed description of the model and its analysis can be found in Appendix C.2. Under this extension, the non-agriculture part of the economy is divided into manufactures, which are assumed to be tradable and can be used for consumption and investment, and services, which are assumed to be nontradable and can only be used for consumption purposes. Interestingly, the main results do not change significantly and trade has very similar effects on the size of agriculture, the real GDP growth rates, as well as intertemporal welfare. Intuitively, the I use data on net agricultural imports to parametrize the two-sector model disciplines the exercise and prevents it from predicting that too much non-agricultural production gets exported. The initial effects

of free trade in South Korea are somewhat smaller in this extension because the differential growth rate of the agricultural price estimated in the three-sector data is lower, which leads to a smaller drop in the initial agricultural share and to a lower intertemporal welfare gain compared to the baseline simulation.

\section{Conclusion}

Many countries have to allocate a large fraction of their resources in agriculture to satisfy their subsistence needs, even when they are particularly unproductive in that sector. If they were open to intersectoral international trade, however, they would be able to import part of their food consumption in exchange of other tradable goods. This article shows that trade did significantly accelerate the transition out-of-agriculture in Great Britain and that it also contributed to the structural transformation of South Korea. Moreover, in South Korea, trade would have played a much larger role if the country had not introduced policies to 
Table 3: Sensitivity of main results to alternative model specifications

\begin{tabular}{|c|c|c|c|c|c|c|c|c|c|c|c|c|c|}
\hline & \multicolumn{8}{|c|}{ South Korea } & \multicolumn{5}{|c|}{ Great Britain } \\
\hline & $\begin{array}{l}S S E_{n} \\
\text { (B.sim) }\end{array}$ & $\begin{array}{l}S S E_{x} \\
\text { (B.sim) }\end{array}$ & $\begin{array}{l}\text { Growth } \\
\text { wrt aut } \\
\text { (B.sim) }\end{array}$ & $\begin{array}{c}\text { Welf. } \\
\text { wrt aut } \\
\text { (B.sim) }\end{array}$ & $\begin{array}{c}\text { Agric. } \\
\text { wrt US } \\
\text { (Aut) }\end{array}$ & $\begin{array}{c}\text { Growth } \\
\text { wrt aut } \\
\text { (FT) }\end{array}$ & $\begin{array}{l}\text { Welf. } \\
\text { wrt aut } \\
\text { (FT) }\end{array}$ & $\begin{array}{c}\text { Agric. } \\
\text { wrt US } \\
\text { (FT) }\end{array}$ & $\begin{array}{l}S S E_{n} \\
(\text { B.sim })\end{array}$ & $\begin{array}{l}S S E_{x} \\
(\text { B.sim) }\end{array}$ & $\begin{array}{l}\text { Growth } \\
\text { wrt aut } \\
\text { (B.sim) }\end{array}$ & $\begin{array}{l}\text { Welf. } \\
\text { wrt aut } \\
\text { (B.sim) }\end{array}$ & $\begin{array}{l}\text { Agric. } \\
\text { wrt US } \\
\text { (Aut) }\end{array}$ \\
\hline Main specification & 1 & 1 & 1.07 & $0.4 \%$ & $+2.9 \mathrm{pp}$ & 1.37 & $8.9 \%$ & $-28 p p$ & 1 & 1 & 1.61 & $5.3 \%$ & $-3.9 \mathrm{pp}$ \\
\hline $\begin{array}{c}\text { Specification with } \\
\text { Stone-Geary pref. }(\varepsilon=1)\end{array}$ & 1 & 1.92 & 1.06 & $0.4 \%$ & $+1.5 \mathrm{pp}$ & 1.36 & $9.2 \%$ & $-28 p p$ & 1 & 0.65 & 1.62 & $5.6 \%$ & $-2.7 p p$ \\
\hline $\begin{array}{l}\text { Specification with common } \\
\text { labor shares }(\beta=1-\alpha)\end{array}$ & 0.60 & 1.71 & 1.02 & $0.3 \%$ & $+4.6 \mathrm{pp}$ & 1.28 & $10 \%$ & $-33 p p$ & 2.2 & 0.94 & 1.38 & $2.3 \%$ & $-8.7 \mathrm{pp}$ \\
\hline $\begin{array}{l}\text { Specification with three } \\
\text { sectors }\end{array}$ & 3.6 & 1.7 & 1.14 & $0.5 \%$ & $+9.7 \mathrm{pp}$ & 1.82 & $7.3 \%$ & $-28 \mathrm{pp}$ & 1.4 & 1.1 & 1.81 & $5.2 \%$ & $-4.5 \mathrm{pp}$ \\
\hline
\end{tabular}

protect its agricultural sector.

In terms of policy implications, in view of these results, one wonders why poor countries import so little food. This question does not have an easy answer and it is likely to be the result of many different factors. Some of these factors, like the perishability of some agricultural goods, do not depend on the government actions, but others like the transport infrastructure quality, intersectoral mobility distortions, or trade restrictions clearly depend on the policies implemented. Concerns about the fall in farmers' earnings or about countries not being self-sufficient and relying on foreign imports for subsistence are often cited to justify distortive policies. ${ }^{25}$ This article is silent about these political economy issues, but it shows that reforms aimed at removing obstacles to international trade in agricultural goods are very beneficial for the overall economy while protectionism towards agriculture reduces aggregate welfare and slows down real income growth.

In terms of future research, one could extend this analysis in many different directions. One such direction could be to incorporate sectoral mobility frictions, which would slow down the reallocation of productive inputs after the trade shock and, consequently, mitigate the effects of a given price change due to international trade. Accordingly, the South Korea

\footnotetext{
${ }^{25}$ See Beghin et al. (2003), for instance, for the case of South Korea.
} 
free trade counterfactual results presented in Section 4.1 could then be re-interpreted as the effects of eliminating trade obstacles and, at the same time, removing mobility frictions. Another extension could be to consider more than one industry in each sector and allow for intrasectoral trade. In this framework, trade would also lead to an increase in the sector-level TFP if it made possible for countries to expand their high-productivity industries and shrink the low-productivity ones. Consequently, the estimated benefits of opening to international trade for growth and welfare would probably be even larger.

\section{Acknowledgements}

I am very grateful to Robert E. Lucas, Jr., Nancy Stokey, Thomas Chaney, and Samuel Kortum for their supervision and support in an earlier version of this article. In addition, I would like to thank the editor, Nathan Nunn for his guidance to improve the article, as well as Francesco Caselli, Fabio Canova, Douglas Gollin, Joseph Kaboski, Kei-Mu Yi, Rachel Ngai, several anonymous referees, and the many people that have provided helpful comments and suggestions. Financial support from "La Caixa", Banco de España, the University of Chicago, Spanish Ministry of Economy and Competitiveness, Grants ECO2012-36719 and ECO2015-66701-R, and Generalitat of Catalonia, Grant SGR2014-493, is gratefully acknowledged. All remaining errors are mine.

\section{References}

Acemoglu, D. and V. Guerrieri (2008). Capital deepening and nonbalanced economic growth. Journal of Political Economy 116(3).

Adamopoulos, T. (2011). Transportation costs, agricultural productivity, and cross-country income differences. International Economic Review 52(2), 489-521.

Alvarez-Cuadrado, F. and M. Poschke (2011). Structural change out of agriculture: Labor push versus labor pull. American Economic Journal: Macroeconomics 3(3), 127-158. 
Arkolakis, C., A. Costinot, and A. Rodríguez-Clare (2012). New trade models, same old gains? The American Economic Review 102(1), 94-130.

Beghin, J. C., J. Bureau, and S. J. Park (2003). Food security and agricultural protection in south korea. American Journal of Agricultural Economics 85(3), 618-632.

Betts, C., R. Giri, and R. Verma (2016). Trade, Reform, and Structural Transformation in South Korea. Manuscript.

Bolt, J. and J. L. Zanden (2014). The maddison project: collaborative research on historical national accounts. The Economic History Review 67(3), 627-651.

Buera, F. and J. Kaboski (2009). Can Traditional Theories of Structural Change Fit the Data? Journal of the European Economic Association 7(2-3), 469-477.

Caselli, F. (2005). Accounting for Income Differences Across Countries. Handbook of Economic Growth. Vol. 1A, ed. Philippe Aghion and Steven Durlauf, 679-741. The Netherlands: North Holland.

Caselli, F. and W. Coleman II (2001). The US structural transformation and regional convergence: A reinterpretation. Journal of Political Economy 109(3).

Connolly, M. and K.-M. Yi (2015). How much of south korea's growth miracle can be explained by trade policy? American Economic Journal: Macroeconomics 7(4), 188-221.

Cooley, T. F. (1995). Frontiers of business cycle research.

Davis, R. (1979). The Industrial Revolution and British Overseas Trade. Leicester University Press.

Deane, P. and W. Cole (1969). British Economic Growth 1688-1959. Cambridge University Press.

Deardorff, A. V. and J. H. Park (2010). A story of trade-induced industrialization. International Economic Journal 24(3), 283-296. 
Dennis, B. N. and T. B. Iscan (2007). Productivity growth and agricultural out-migration in the united states. Structural Change and Economic Dynamics 18(1), 52-74.

Dennis, B. N. and T. B. İşcan (2009). Engel versus baumol: Accounting for structural change using two centuries of us data. Explorations in Economic history 46(2), 186-202.

Dessy, S., M. F. and S. Pallage (2010). On the mechanics of trade-induced structural transformation. Journal of Macroeconomics 32(1), 251-264.

Diao, X., D. J., D. Skully, A. Somwaru, and C. Lee (2002). Structural change and agricultural protection: costs of Korean agricultural policy, 1975 and 1990. US Department of Agriculture, Economic Research Service, Washington. AER report 809.

Duarte, M. and D. Restuccia (2010). The Role of the Structural Transformation in Aggregate Productivity. Quarterly Journal of Economics 125(1), 129-173.

Echevarria, C. (1997). Changes in sectoral composition associated with economic growth. International Economic Review 38(2), 431-452.

Echevarria, C. (2008). International trade and the sectoral composition of production. Review of Economic Dynamics 11(1), 192-206.

Feinstein, C. H. (1988). National Statistics, 1760-1920. in Charles H. Feinstein and Sidney Pollard, eds., Studies in Capital Formation in the United Kingdom, 1750-1920.

Gollin, D., S. Parente, and R. Rogerson (2004). Farm work, home work and international productivity differences. Review of Economic Dynamics 7(4), 827-850.

Gollin, D., S. Parente, and R. Rogerson (2007). The food problem and the evolution of international income levels. Journal of Monetary Economics 54(4), 1230-1255.

Hayashi, F. and E. Prescott (2008). The depressing effect of agricultural institutions on the prewar japanese economy. Journal of Political Economy 116(4). 
Herrendorf, B., R. Rogerson, and A. Valentinyi (2013). Two perspectives on preferences and structural transformation. The American Economic Review 103(7), 2752-2789.

Herrendorf, B., R. Rogerson, and Á. Valentinyi (2014). Growth and structural transformation. Handbook of Economic Growth 2, 855-941.

Johnston, B. F. and J. W. Mellor (1961). The role of agriculture in economic development. The American Economic Review 51(4), 566-593.

Kendrick, J. W. (1961). Productivity Trends in the United States. Princeton University Press.

Kim, K. S. and S. D. Hong (1997). Accounting for Rapid Economic Growth in Korea, 1963-1995. Korea Development Institute.

Kongsamut, P., S. Rebelo, and D. Xie (2001). Beyond balanced growth. Review of Economic Studies, 869-882.

Matsuyama, K. (1992). Agricultural productivity, comparative advantage, and economic growth. Journal of Economic Theory 58(2), 317-334.

Matsuyama, K. (2009). Structural Change in an Interdependent World: A Global View of Manufacturing Decline. Journal of the European Economic Association 7(2-3), 478-486.

Mitchell, B. (1962). Abstract of British Historical Statistics. Cambridge University Press.

Ngai, L. and C. Pissarides (2007). Structural change in a multisector model of growth. American Economic Review 97(1), 429-443.

Prescott, E. C. (1986). Theory ahead of business-cycle measurement. In Carnegie-Rochester conference series on public policy, Volume 25, pp. 11-44. Elsevier.

Restuccia, D., D. Yang, and X. Zhu (2008). Agriculture and aggregate productivity: A quantitative cross-country analysis. Journal of Monetary Economics 55(2), 234-250.

Schultz, T. (1953). The economic organization of agriculture. McGraw-Hill. 
Sposi, M. (2012). Evolving Comparative Advantage, Structural Change, and the Composition of Trade. Manuscript.

Sposi, M. J. (2016). Evolving comparative advantage, sectoral linkages, and structural change. Manuscript.

Stefanski, R. (2014). Structural transformation and the oil price. Review of Economic Dynamics 17(3), 484-504.

Stokey, N. (2001). A quantitative model of the British industrial revolution, 1780-1850. In Carnegie-Rochester Conference Series on Public Policy, Volume 55, pp. 55-109. Citeseer.

Święcki, T. (2017). Determinants of structural change. Review of Economic Dynamics 24, 95-131.

Timmer, M., G. d. Vries, and K. d. Vries (2014). Patterns of structural change in developing countries.

Tombe, T. (2015). The missing food problem: Trade, agriculture, and international productivity differences. American Economic Journal: Macroeconomics 7(3), 226-258.

Uy, T., K. M. Yi, and J. Zhang (2013). Structural change in an open economy. Journal of Monetary Economics 60(6), 667-682.

Valentinyi, A. and B. Herrendorf (2008). Measuring factor income shares at the sectoral level. Review of Economic Dynamics 11(4), 820-835.

Ward, T. (2004). The corn laws and english wheat prices, 1815-1846. Atlantic economic journal 32(3), 245-255. 


\section{Appendices}

\section{A Equilibrium Analysis}

\section{A.1 Agents' Optimization}

Households choose the amount to consume of each good, the amount to to invest for future consumption, as well as the sector to rent the inputs they own for all time periods. They do so to maximize their intertemporal utility function in Equation (2) subject to their budget constraint in Equation (3), which gives the following three conditions in terms of the control variables $c_{1}$ and $c_{2}$, the state variable $k$, and the co-state variable $\lambda$ :

$$
\begin{gathered}
c_{1}=\omega q^{-\varepsilon} c_{2}+\overline{c_{1}}, \\
c_{2}=\lambda\left(1+\omega q^{1-\varepsilon}\right)^{-1}, \\
\frac{d \lambda}{d t}=\lambda(\delta+\rho-R) .
\end{gathered}
$$

Equation (3) together with Equations (10) - (12), the initial condition $k(0)=k_{0}$ and the transversality condition

$$
\lim _{t \rightarrow \infty}\left\{\exp \left(-\int_{0}^{t}(R(s)-\nu-\delta) d s\right) \frac{k(t)}{c_{2}(t)}\right\}=0
$$

determine the solution to the representative household optimization problem.

Firms choose the amount of inputs they want to hire each period in order to maximize their static profits. At the optimum, they choose the amount of capital and labor in each sector so that their marginal products are equalized:

$$
\frac{\partial y_{2}}{\partial k_{2}}=q \frac{\partial y_{1}}{\partial k_{1}}=R
$$

and

$$
\frac{\partial y_{2}}{\partial n_{2}}=q \frac{\partial y_{1}}{\partial n_{1}}=w
$$

with the production functions defined in Equations (4)and (5).

\section{A.2 Closed Economy Equilibrium Analysis}

The market clearing conditions in the closed economy equilibrium state that the labor input hired by agricultural firms plus the labor input hired by nonagricultural firms is equal 
to the labor supply,

$$
n_{1}+n_{2}=1
$$

the capital units hired by firms in the agricultural sector plus the capital units hired by firms in the nonagricultural sector are equal to the total capital stock,

$$
k_{1}+k_{2}=k
$$

the domestic demand of agricultural good is equal to its domestic supply

$$
c_{1}=y_{1},
$$

and, finally, the domestic demand of nonagricultural good is equal to its domestic supply,

$$
c_{2}+\frac{d k}{d t}+(\delta+\nu) k=y_{2}
$$

The closed economy equilibrium conditions, defined in Equations (10) - (19), can be summarized by a system of six equations in the six unknowns $\left[k(t), \lambda(t), c_{2}(t), n(t), \kappa(t)\right.$, $q(t)]_{t \geq 0}$ :

$$
\begin{aligned}
\frac{d k}{d t} & =((1-\kappa) k)^{\alpha}\left(A_{2}(1-n)\right)^{1-\alpha}-(\delta+\nu) k-c_{2} \\
\frac{d \lambda}{d t} & =\lambda\left(\rho+\delta-\alpha((1-\kappa) k)^{\alpha}\left(A_{2}(1-n)\right)^{1-\alpha}\right) \\
c_{2} & =\lambda^{-1}\left(1+\omega q^{1-\varepsilon}\right)^{-1} \\
\frac{1-n}{1-\kappa} & =\frac{(1-\alpha)}{\alpha} \frac{\eta}{\beta} \frac{n}{\kappa} \\
\omega q^{1-\varepsilon} c_{2} & =q\left((\kappa k)^{\eta}\left(A_{1} n\right)^{\beta} N^{\eta+\beta-1}-\overline{c_{1}}\right) \\
q & =\left(\frac{\alpha}{\eta}\right)^{\alpha}\left(\frac{1-\alpha}{\beta}\right)^{1-\alpha}(\kappa k)^{\alpha-\eta} n^{1-\alpha-\beta} A_{2}^{1-\alpha} A_{1}^{-\beta} N^{1-\eta-\beta},
\end{aligned}
$$

where $\kappa \equiv \frac{k_{1}}{k}$ and $n \equiv n_{1}$, together with the boundary conditions $k(0)=0$ and equation (13).

We can now rewrite this closed economy equilibrium system in terms of the detrended 
variables $\widehat{c_{2}}=\frac{c_{2}}{A_{2}}, \widehat{k}=\frac{k}{A_{2}}, \widehat{\lambda}=\lambda A_{2}, \widehat{q}=\frac{q}{z}$, where $z \equiv A_{2}^{1-\eta} A_{1}^{-\beta} N^{1-\eta-\beta}$ :

$$
\begin{aligned}
\frac{d \widehat{k}}{d t} & =((1-\kappa) \widehat{k})^{\alpha}(1-n)^{1-\alpha}-\left(\delta+\nu-\gamma_{2}\right) \widehat{k}-\widehat{c_{2}} \\
\frac{d \widehat{\lambda}}{d t} & =\widehat{\lambda}\left(\rho+\delta+\gamma_{2}-\alpha((1-\kappa) \widehat{k})^{\alpha}(1-n)^{1-\alpha}\right) \\
\widehat{c_{2}} & =\widehat{\lambda}^{-1}\left(1+\omega \widehat{q}^{1-\varepsilon} z^{1-\varepsilon}\right)^{-1} \\
n & =\frac{\kappa}{\kappa+\frac{1-\alpha}{\alpha} \frac{\eta}{\beta}(1-\kappa)} \\
\omega \widehat{q}^{1-\varepsilon} z^{1-\varepsilon} \widehat{c_{2}} & =\widehat{q}(\kappa \widehat{k})^{\eta} n^{\beta}-\widehat{q} \frac{z}{A_{2}} \overline{c_{1}} \\
\widehat{q} & =\left(\frac{\alpha}{\eta}\right)^{\alpha}\left(\frac{1-\alpha}{\beta}\right)^{1-\alpha}(\kappa \widehat{k})^{\alpha-\eta} n^{1-\alpha-\beta} .
\end{aligned}
$$

Note that if $(1-\eta) \gamma_{2}+(1-\eta-\beta) \nu-\beta \gamma_{1}<0, \lim _{t \rightarrow \infty} z=0$. Hence, when $\varepsilon<1$ and $\gamma_{2}>0$, equation (24) implies that $\lim _{t \rightarrow \infty} \widehat{q}(\kappa \widehat{k})^{\eta} n^{\beta}=0$. From equation (25), we then get that $\lim _{t \rightarrow \infty}(\kappa \widehat{k})^{\alpha} n^{1-\alpha}=0$. This, together with equation (23), leads to $\lim _{t \rightarrow \infty} \kappa=\lim _{t \rightarrow \infty} n=0$ and to $\lim _{t \rightarrow \infty} \hat{q}=0$. Finally, from equation (22), we get $\lim _{t \rightarrow \infty} \widehat{\lambda}=1 / \widehat{c_{2}}$.

Hence, the detrended system converges asymptotically to an equilibrium where all the production inputs are allocated to the nonagricultural sector. In the steady state of this asymptotic equilibrium, i.e. when $\dot{\widehat{k}}=\dot{\hat{\lambda}}=0$,

$$
\begin{aligned}
\widehat{k}^{s s} & =\left(\frac{\alpha}{\delta+\rho+\gamma_{2}}\right)^{1 /(1-\alpha)} \\
{\widehat{c_{2}}}^{s s} & =\left(\widehat{k}^{s s}\right)^{\alpha}-\left(\delta+\nu+\gamma_{2}\right) \widehat{k}^{s s} .
\end{aligned}
$$

\section{A.3 Small Open Economy Equilibrium Analysis}

In the small open economy equilibrium, the market clearing conditions are the input markets equilibrium conditions in equations (16) and (17) together with the agricultural good market equilibrium condition,

$$
c_{1}+x_{1}=y_{1}
$$

and the nonagricultural good market equilibrium condition

$$
c_{2}+\frac{d k}{d t}+(\delta+\nu) k+x_{2}=y_{2}
$$


where $x_{1}$ denote the net exports of agricultural good and $x_{2}$ the net exports of nonagricultural good. The trade balance condition can be written as

$$
q x_{1}+x_{2}=0 .
$$

The open economy equilibrium conditions, defined in equations (10) - (17) and (26) (28), can be summarized by a system of six equations in six the unknowns $\left[k(t), \lambda(t), c_{2}(t)\right.$, $\left.x_{2}(t), n(t), \kappa(t)\right]_{t \geq 0}$ :

$$
\begin{aligned}
\frac{d k}{d t} & =((1-\kappa) k)^{\alpha}\left(A_{2}(1-n)\right)^{1-\alpha}-(\delta+\nu) k-c_{2}-x_{2} \\
\frac{d \lambda}{d t} & =\lambda\left(\rho+\delta-\alpha((1-\kappa) k)^{\alpha}\left(A_{2}(1-n)\right)^{1-\alpha}\right) \\
c_{2} & =\lambda^{-1}\left(1+\omega q^{1-\varepsilon}\right)^{-1} \\
\frac{1-n}{1-\kappa} & =\frac{(1-\alpha)}{\alpha} \frac{\eta}{\beta} \frac{n}{\kappa} \\
\omega q^{1-\varepsilon} c_{2}-x_{2} & =q\left((\kappa k)^{\eta}\left(A_{1} n\right)^{\beta} N^{\eta+\beta-1}-\overline{c_{1}}\right) \\
q & =\left(\frac{\alpha}{\eta}\right)^{\alpha}\left(\frac{1-\alpha}{\beta}\right)^{1-\alpha}(\kappa k)^{\alpha-\eta} n^{1-\alpha-\beta} A_{2}^{1-\alpha} A_{1}^{-\beta} N^{1-\eta-\beta},
\end{aligned}
$$

where $\kappa \equiv \frac{k_{1}}{k}$ and $n \equiv n_{1}$, together with the boundary conditions $k(0)=0$ and equation (13).

As before, we can rewrite this equilibrium system in terms of the detrended variables $\widehat{c_{2}}=\frac{c_{2}}{A_{2}}, \widehat{x_{2}}=\frac{x_{2}}{A_{2}}, \widehat{k}=\frac{k}{A_{2}}, \widehat{\lambda}=\lambda A_{2}$ :

$$
\begin{aligned}
\frac{d \widehat{k}}{d t} & =((1-\kappa) \widehat{k})^{\alpha}(1-n)^{1-\alpha}-\left(\delta+\nu-\gamma_{2}\right) \widehat{k}-\widehat{c_{2}}-\widehat{x_{2}} \\
\frac{d \widehat{\lambda}}{d t} & =\widehat{\lambda}\left(\rho+\delta+\gamma_{2}-\alpha((1-\kappa) \widehat{k})^{\alpha}(1-n)^{1-\alpha}\right) \\
\widehat{c_{2}} & =\widehat{\lambda}^{-1}\left(1+\omega \widehat{q}^{1-\varepsilon} z^{1-\varepsilon}\right)^{-1} \\
\frac{1-n}{1-\kappa} & =\frac{(1-\alpha)}{\alpha} \frac{\eta}{\beta} \frac{n}{\kappa} \\
\omega q^{1-\varepsilon} \widehat{c_{2}} & =\frac{q}{z}(\kappa \widehat{k})^{\eta} n^{\beta}-\frac{q}{A_{2}} \frac{c_{1}}{}+\widehat{x_{2}} \\
\frac{q}{z} & =\left(\frac{\alpha}{\eta}\right)^{\alpha}\left(\frac{1-\alpha}{\beta}\right)^{1-\alpha}(\kappa \widehat{k})^{\alpha-\eta} n^{1-\alpha-\beta},
\end{aligned}
$$

where $z \equiv A_{2}^{1-\eta} A_{1}^{-\beta} N^{1-\eta-\beta}$, as before.

Note that if $(1-\eta) \gamma_{2}+(1-\eta-\beta) \nu-\beta \gamma_{1}>\gamma_{q}, \lim _{t \rightarrow \infty} \frac{q}{z}=0$. This leads to $\lim _{t \rightarrow \infty}(\kappa \widehat{k})^{\alpha-\eta} n^{1-\alpha-\beta}=$ 0 , from equation (34). Using also equation (32), this implies that $\lim _{t \rightarrow \infty} \kappa=\lim _{t \rightarrow \infty} n=0$. More- 
Table 4: South Korea data sources

\begin{tabular}{cccc}
\hline Variable & Description & Period & Source \\
\hline \hline$N$ & Total population & $1960-2015$ & Bank of Korea \\
$P_{1} Y_{1}, P_{2} Y_{2}$ & Nominal GDP by sector & $1963-2015$ & Bank of Korea \\
$Y_{1}, Y_{2}$ & Real GDP by sector & $1963-2015$ & Bank of Korea \\
$n_{1}, n_{2}$ & Employment share by sector & $1963-2015$ & ILOSTAT \\
& & $1963-1970$ & Economic Statistics Yearbooks \\
$P_{1} x_{1}$ & Agricultural net imports & $1973-2015$ & Bank of Korea \\
& & $1963-1970$ & Korea Development Institute \\
$K$ & Capital & $1970-2015$ & Bank of Korea \\
\hline
\end{tabular}

over, when $\varepsilon<1, \gamma_{q}<0$, and $\gamma_{2}>0$, we get $\lim _{t \rightarrow \infty} \widehat{x_{2}}=0$ from equation (33), and $\lim _{t \rightarrow \infty} \widehat{\lambda}=1 / \widehat{c_{2}}$ from equation (31). Thus, as in the closed economy case, the detrended system converges asymptotically to an equilibrium where all the production inputs are allocated to the nonagricultural sector. In the steady state of this asymptotic equilibrium, i.e. when $\widehat{k}=\hat{\lambda}=0$,

$$
\begin{aligned}
\widehat{k}^{s s} & =\left(\frac{\alpha}{\delta+\rho+\gamma_{2}}\right)^{1 /(1-\alpha)} \\
{\widehat{c_{2}}}^{s s} & =\left(\widehat{k}^{s s}\right)^{\alpha}-\left(\delta+\nu+\gamma_{2}\right) \widehat{k}^{s s}
\end{aligned}
$$

which also corresponds to the closed economy steady state.

\section{B Exogenous Variables and Data Sources}

\section{B.1 South Korea Exogenous Variables}

This section describes the construction and data sources of the exogenous variables used in the simulations of South Korea (that is, total population, agricultural relative price, agricultural TFP, and nonagricultural TFP) as well as the data sources of other time series used to compare the fit of the model with the actual data. The information is summarized in Table 4, and the plots of the main variables are shown in Figure 6, where the dotted lines are the measured series and the solid lines are the fitted series under constant growth.

Data on total population is available for the entire sample period from the Bank of Korea Economic Statistics System (ECOS), while employment data (by economic activity) is obtained from the International Labour Organization (ILOSTAT). ${ }^{26}$ Data on current and constant prices GDP by industry is also available from ECOS, where the agricultural sector is defined as Agriculture, Forestry and Fishing, and the nonagricultural sector is the rest of the economy. Data for aggregate physical capital is obtained from Kim and Hong (1997) for

\footnotetext{
${ }^{26}$ http:/ /ecos.bok.or.kr/EIndex_en.jsp and https://www.ilo.org/ilostat.
} 
Figure 6: South Korea exogenous variables
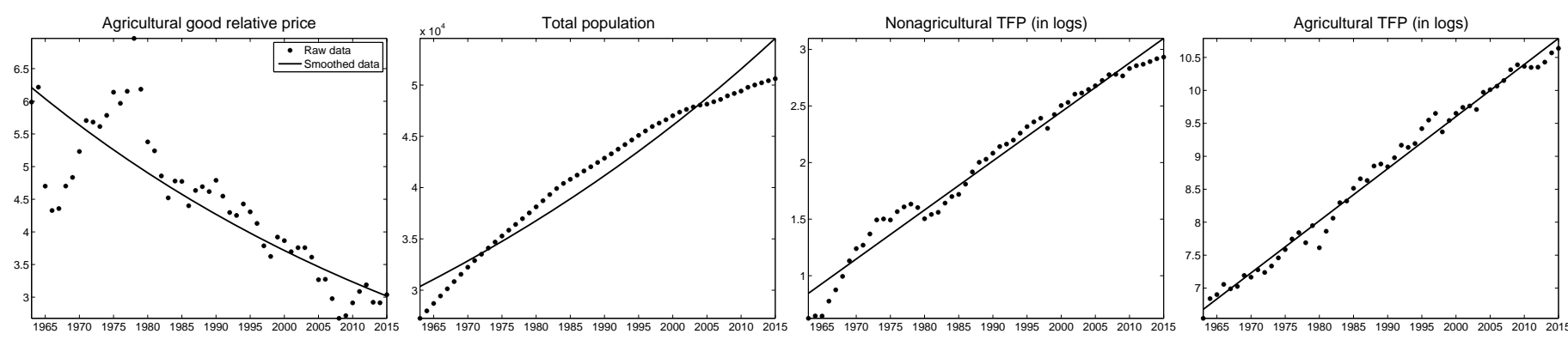

the period 1963-1970 (Net Fixed Capital Stock of Nonresidential Business at constant prices plus Total Inventories for Nonresidential Business at Constant Prices), and from ECOS for the period 1973-2015 (Non-Residential Construction, plus Other Constructions, plus Transport Equipment, plus Other Equipment, plus Inventories at chained prices). Finally, data on agricultural imports and exports are obtained from Input-Output tables in the Economic Statistics Yearbooks for the years 1963, 1968, and 1970, as well as from the Input-Output tables in ECOS for many years between 1973 and 2015, using the categories Crops, Livestock breeding, Forestry products, and Fishery products.

Since data on the relative price of the agricultural good is not directly available, I construct it by dividing the agricultural sector GDP deflator by the GDP deflator of the rest of the economy, where the sectoral GDP deflator is computed as the nominal GDP data over the real GDP data for each sector. Similarly, since data on agricultural and nonagricultural Total Factor Productivity are not available either, I infer them using equations (4) and (5) together with data on sectoral real GDP, sectoral employment, and total capital, assuming that capital is efficiently allocated across sectors. ${ }^{27}$

\section{B.2 Great Britain Exogenous Variables}

This section of the appendix describes the construction of the exogenous variables used in the simulations of Great Britain, as well as their data sources. Table 5 summarizes the data sources, and Figure 7 plots the measured data (dotted lines) together with the fitted series under constant growth (solid lines).

Data on total population, total employment, real GDP, and nominal GDP are available from Deane and Cole (1969) every ten years for the entire sample period. Deane and Cole (1969) also contain information of the share of Agriculture, Forestry and Fishing in total employment and total GDP. The data used for the aggregate capital stock is from Feinstein (1988), and it corresponds to total net stock of domestic reproducible fixed assets at con-

\footnotetext{
${ }^{27}$ Note that the measured agricultural TFP in this case corresponds to the term $\left(A_{1}\right)^{\beta}$ in equation (5) times the term $\left(\frac{L}{N}\right)^{1-\eta-\beta}$. This is not a problem in terms of the estimation because total land is assumed to be constant over time.
} 
Table 5: Great Britain data sources

\begin{tabular}{cccc}
\hline Variable & Description & Period & Source \\
\hline \hline$N$ & Total population & $1800-1900$ & Deane and Cole (1969) \\
$n_{1}, n_{2}$ & Employment by sector & $1800-1900$ & Deane and Cole (1969) \\
$P Y$ & Nominal GDP & $1800-1900$ & Deane and Cole (1969) \\
$Y$ & Real GDP & $1800-1900$ & Deane and Cole (1969) \\
$P_{1}$ & Price level agriculture & $1800-1900$ & Mitchell (1962) \\
$P_{1} x_{1}$ & Agricultural net imports & $1805-1855$ & Davis (1979) \\
$K$ & Real net capital stock & $1800-1900$ & Feinstein (1988) \\
\hline
\end{tabular}

stant prices, subtracting the category dwellings. It is equal to the sum of Industrial and Commercial Buildings, Other Nonresidential Buildings and Works, Plant Machinery and Equipment, Rolling Stock and vehicles, and Ships and it is available for Great Britain for the subperiod 1800-1860. I then extend the series until 1900 using the capital stock series for the United Kingdom from Feinstein (1988), assuming that the share corresponding to Great Britain is equal to the one in periods where the series for both Great Britain and the United Kingdom are available (which is 95\% for the years 1850 and 1860). Finally, data on net agricultural imports is obtained from Davis (1979), computed as the sum of net agricultural imports of foodstuffs plus raw materials, for the years 1805 - 1855. Since the series from year 1835 onwards do not include trade with Ireland, I estimate the net agricultural imports from Ireland assuming that its share in the total is equal to the average until year 1825 (which is equal to $6.5 \%$ ).

Real GDP in agriculture is computed by dividing nominal GDP in agriculture by the price level in agricultural, which is available from Mitchell (1962) for the entire sample period. Real GDP in the nonagricultural sector is then obtained obtained by subtracting the real GDP in agriculture from aggregate real GDP. Using data on aggregate capital and employment by sector it is possible to infer the level of capital by sector, by assuming that capital is efficiently allocated. I then construct the agricultural and nonagricultural TFP series using the production functions defined equations (4) and (5), together with data on real GDP by sector, employment by sector, and total stock of capital. Finally, to compute the relative price of the agricultural good, I divide the agricultural price level - which is available in Mitchell (1962) for the period 1800 - 1900 - by the GDP deflator of the nonagricultural sector. The latter is constructed by dividing nominal GDP outside agriculture by the real GDP outside agriculture, both of which are obtained by subtracting the agricultural GDP to the aggregate GDP.

To construct the plots in Figures 1 and 5, I extend the agricultural employment share 
Figure 7: Great Britain exogenous variables
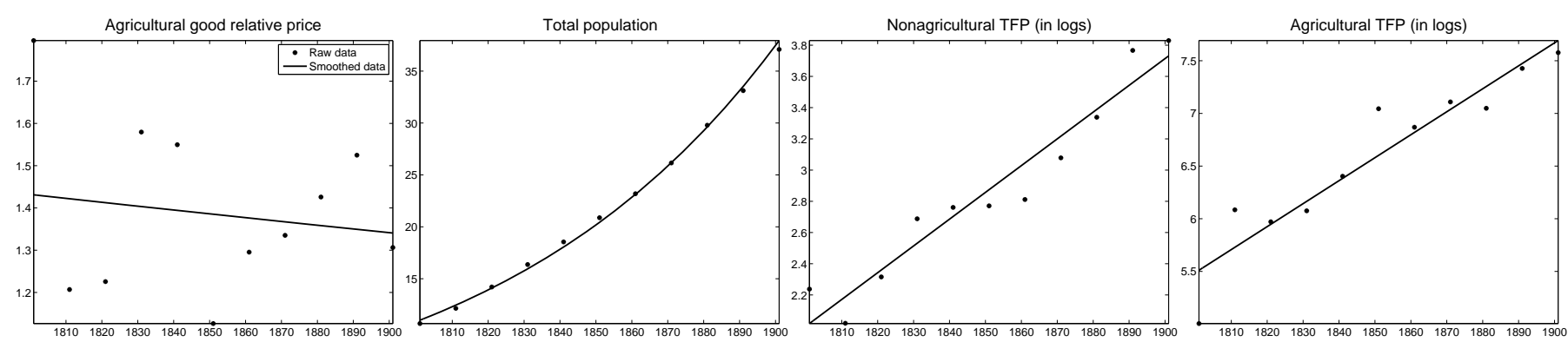

data using the GGDC 10-sector database (see Timmer et al. (2014)).

\section{B.3 United States Exogenous Variables}

The data source of Figure 1 for the United States agricultural employment is from the Historical Statistics of the United States - Millennial Edition Online (see http: / hsus.cambridge.org), Kendrick (1961), and the U.S. Buereau of Economic Analysis - NIPA tables. The United States income data is from Maddison Project (see Bolt and Zanden (2014)), which is also the data source used to extend the Great Britain income data after 1900 and to make the income data for the the three countries (United States, Great Britain, and South Korea) comparable.

\section{Alternative Model Specifications}

\section{C.1 Analysis of the Model with Stone-Geary Preferences}

\section{C.1.1 Model Setup}

Under the Stone-Geary preference specification, the $N(t)$ infinitely-lived members of the representative household derive utility from the following function:

$$
\begin{aligned}
U(0) & =\int_{0}^{\infty} e^{-(\rho-\nu) t} \log (\tilde{c}) d t, \text { where } \\
\tilde{c} & =\omega \log \left(c_{1}-\overline{c_{1}}\right)+\log \left(c_{2}\right) .
\end{aligned}
$$

This corresponds to the preferences in equations 1 and 2 when $\varepsilon=1$. 


\section{C.1.2 Closed Economy Competitive Equilibrium}

The equilibrium system of the closed economy is almost identical to the one described in Appendix A.2. In terms of detrended variables, the only differences are in equations (22) and (24), which now become

$$
\widehat{c_{2}} \widehat{\lambda}(1+\omega)=1
$$

and

$$
\omega \widehat{c_{2}}=\widehat{q}(\kappa \widehat{k})^{\eta} n^{\beta}-\widehat{q} \frac{z}{A_{2}} \overline{c_{1}} .
$$

As a result, the Closed-Economy asymptotic steady state is given the following system of equations:

$$
\begin{aligned}
\omega \widehat{c}_{2}^{s s}\left(\frac{\eta}{\alpha}\right)^{\alpha}\left(\frac{\beta}{1-\alpha}\right)^{1-\alpha} & =\left(\kappa^{s s} \widehat{k}^{s s}\right)^{\alpha}\left(n^{s s}\right)^{1-\alpha} \\
\alpha\left(\left(1-\kappa^{s s}\right) \widehat{k}^{s s}\right)^{\alpha}\left(1-n^{s s}\right)^{1-\alpha} & =\rho+\delta+\gamma_{2} \\
\frac{1-n^{s s}}{1-\kappa^{s s}} & =\frac{(1-\alpha)}{\alpha} \frac{\eta}{\beta} \frac{n^{s s}}{\kappa^{s s}} \\
{\widehat{c_{2}}}^{s s} & =\left(\left(1-\kappa^{s s}\right) \widehat{k}^{s s}\right)^{\alpha}\left(1-n^{s s}\right)^{1-\alpha}-\left(\delta+\nu-\gamma_{2}\right) \widehat{k}^{s s} \\
\widehat{\lambda}^{s s} & =\frac{1}{(1+\omega){\widehat{c_{2}}}^{s s}} .
\end{aligned}
$$

Note that this is different than the one described in Appendix A.2.

\section{C.1.3 Small Open Economy Competitive Equilibrium}

Similarly, the equilibrium system of the small open economy is almost identical to the one described in Appendix A.3. In terms of detrended variables, the one differences are in Equations (31) and (33), which now become

$$
\widehat{c_{2}} \widehat{\lambda}(1+\omega)=1
$$

and

$$
\omega \widehat{c_{2}}=\widehat{q}(\kappa \widehat{k})^{\eta} n^{\beta}-\widehat{q} \frac{z}{A_{2}} \overline{c_{1}}+\widehat{x_{2}} .
$$


As a result, the Small-Open Economy asymptotic steady state is given by

$$
\begin{aligned}
n^{s s} & =\kappa^{s s}=0 \\
\widehat{x_{2}} & =\omega \widehat{c_{2}} \\
\widehat{k}^{s s} & =\left(\frac{\alpha}{\delta+\rho+\gamma_{2}}\right)^{1 /(1-\alpha)} \\
{\widehat{c_{2}}}^{s s} & =\frac{1}{1+\omega}\left(\left(\widehat{k}^{s s}\right)^{\alpha}-\left(\delta+\nu+\gamma_{2}\right) \widehat{k}^{s s}\right) \\
\widehat{\lambda}^{s s} & =\frac{1}{(1+\omega) \widehat{c}_{2}^{s s}} .
\end{aligned}
$$

Hence, under these preferences, the closed and open economy steady states are different.

\section{C.2 Analysis and Main Results of the Model with Three Sectors}

\section{C.2.1 Model Setup}

Households' description. The $N(t)$ infinitely-lived members of the representative household derive now utility from consuming three goods:

$$
\begin{aligned}
U(0) & =\int_{0}^{\infty} e^{-(\rho-\nu) t} \log (\tilde{c}) d t, \text { where } \\
\tilde{c} & =\left[\omega_{1}^{\frac{1}{\epsilon}}\left(c_{1}-\overline{c_{1}}\right)^{\frac{\varepsilon-1}{\varepsilon}}+\omega_{2}^{\frac{1}{\epsilon}} c_{2}^{\frac{\varepsilon-1}{\varepsilon}}+\omega_{3}^{\frac{1}{\epsilon}}\left(c_{3}+\overline{c_{3}}\right)^{\frac{\varepsilon-1}{\varepsilon}}\right]^{\frac{\varepsilon}{\varepsilon-1}}, \varepsilon \in[0, \infty),
\end{aligned}
$$

where $\nu$ denotes the population growth rate and $e^{\nu t}$ is total population because the initial population is normalized to 1 . The variables $c_{1}, c_{2}$, and $c_{3}$ denote the amount of agricultural good, manufacturing good, and service good, respectively, consumed by each member of the household member. The parameter $\varepsilon$ is the elasticity of substitution between the three goods when $\overline{c_{1}}=\overline{c_{3}}=0, \rho$ is the intertemporal discount factor, and $\nu$ is population growth. The parameters $\underline{c_{1}}$ and $\overline{c_{3}}$ make the preferences non-homothetic: when $\overline{c_{1}}>0$ and $\overline{c_{3}}>0$, the agricultural good expenditure share in falls with income while the service good one increases. They can be respectively interpreted as the agricultural good subsistence consumption and the initial endowment of services.

As in the two-sector model, households own the stocks of capital and land, which they supply to firms together with their labor endowment. At each period, household choose their consumption of the three goods and their savings, as well as the sector at which they rent the inputs they own. In the model, inputs are perfectly mobile across sector, which implies that there is a unique wage rate $w$, capital rental rate $R$, and land rental rate $p$. The 
period-by-period household budget constraint, expressed in per capita terms, is given by

$$
\frac{d k}{d t}=w+(R-\delta-\nu) k+p\left(\frac{L}{N}\right)-q_{1} c_{1}-c_{2}-q_{3} c_{3},
$$

where the price of the nonagricultural good is normalized to $1, q_{1}$ and $q_{3}$ denote the price of the agricultural good and service good relative to the manufacturing good, $L / N$ the stock of land per capita, and $\delta$ the capital depreciation rate. All the variables are time functions except for the parameter $\delta$ and the land stock $L$, which are constant.

The optimization problem of a representative household consists on choosing $\left[c_{1}(t)\right.$, $\left.c_{2}(t), c_{3}(t), k(t)\right]_{t \geq 0}$ to maximize Equation (37) subject to Equation (38) and given an initial $k_{0}$.

Firms' description. In the model, there are also many identical firms in each sector. The production functions for the manufacturing and service goods are given by

$$
y_{j}=\left(k_{j}\right)^{\alpha}\left(A_{j} n_{j}\right)^{1-\alpha}, \quad j=2,3,
$$

while the agricultural good production function is given by

$$
y_{1}=\left(k_{1}\right)^{\eta}\left(A_{1} n_{1}\right)^{\beta}\left(\frac{L}{N}\right)^{1-\eta-\beta},
$$

where $y_{j}$ denotes output, $A_{j}$ the total factor productivity, $k_{j}$ the stock of capital per capita, and $n_{j}$ the fraction of labor employed in sector $j$. The per-capita land stock, $L / N$, falls over time because the stock of land is fixed and population growth is positive. Total factor productivity grows exogenously in all sectors at (potentially different) rates $\gamma_{1}, \gamma_{2}$, and $\gamma_{3}$. Mathematically,

$$
\gamma_{j} \equiv \frac{d A_{j} / d t}{A_{j}}, \quad j=1,2,3 .
$$

The optimization problem of firms consists on choosing the amount of labor and capital to hire in order to maximize their profits. Since firms exhibit constant returns to scale and there is perfect competition, the total number of firms is irrelevant for the equilibrium and, therefore, we can solve for the competitive equilibrium as if there was a representative firm in each sector.

\section{C.2.2 Closed Economy Competitive Equilibrium}

A competitive equilibrium for the closed economy, given the initial capital stock $k_{0}$ and the exogenous variables $\left[A_{1}(t), A_{2}(t), A_{3}(t), N(t)\right]_{t \geq 0}$, are a set of prices $\left[w(t), R(t), q_{1}(t)\right.$, 
$\left.q_{3}(t), p(t)\right]_{t \geq 0}$ and quantities $\left[y_{1}(t), y_{2}(t), y_{3}(t), c_{1}(t), c_{2}(t), c_{3}(t), n_{1}(t), n_{2}(t), n_{3}(t), k_{1}(t)\right.$, $\left.k_{2}(t), k_{3}(t), k(t)\right]_{t \geq 0}$ which satisfy the consumer optimization conditions, the firm optimization conditions and the market clearing conditions. The market clearing conditions guarantee that the amount of goods and inputs supplied domestically is equal to the amount demanded domestically. Appendix A contains a detailed description of the closed economy equilibrium conditions.

In terms of the long-run equilibrium, if the three consumption goods are complements in the households' preferences, i.e. $0<\varepsilon<1$, there is TFP growth in all sectors (i.e., $\gamma_{1}>0$, $\gamma_{2}>0$, and $\gamma_{3}>0$ ), TFP grows faster in manufactures than in services (i.e., $\gamma_{2}>\gamma_{3}$ ) and the following condition is satisfied

$$
(\alpha-\eta) \gamma_{2}+(1-\alpha) \gamma_{3}+(1-\eta-\beta) \nu-\beta \gamma_{1}<0
$$

then the economy converges to an asymptotic steady state where the share of inputs allocated to the agricultural sector is zero while the other two sectors have positive and constant input shares. Equation (42) states that agricultural TFP growth must be large enough relative to the to the TFP growth rate of the other two sectors and to population growth, implying that the ratio $\frac{q_{1}}{q_{3}}$ converges to zero asymptotically. These conditions guarantee that consumption increases over time for all goods, implying that the non-homothetic terms $\overline{c_{1}}$ and $\overline{c_{3}}$ become less and less important over time and, in the limit, the economy behaves as if the term $\tilde{c}$ in Equation (37) was $\tilde{c}=\left[\omega_{1}^{\frac{1}{\epsilon}}\left(c_{1}\right)^{\frac{\varepsilon-1}{\varepsilon}}+\omega_{2}^{\frac{1}{\epsilon}}\left(c_{2}\right)^{\frac{\varepsilon-1}{\varepsilon}}+\omega_{3}^{\frac{1}{\epsilon}}\left(c_{3}\right)^{\frac{\varepsilon-1}{\varepsilon}}\right]^{\frac{\varepsilon}{\varepsilon-1}}$. Asymptotically, the expenditure share of services converges to one but some resources have to allocated to the manufacturing sector for the production of capital, leading both sectors to survive asymptotically.

During the transition, there are two forces that may lead to structural transformation in a closed economy, one of them being changes in income and the other one being changes in relative prices. As households' get richer, due to non-homothetic preferences, their consumption expenditure share decreases for the agricultural good and increases for the service good, since the agricultural good has the lowest income elasticity and the service good the highest. This is the income effect, which would not exist if $\underline{c_{1}}=\overline{c_{3}}=0$. At the same time, whenever $\varepsilon \neq 1$, the sectoral reallocation in an economy are also affected by changes in the relative prices. In the case of $\varepsilon<1$, i.e. when the three consumption goods are complements, the relative price effect also makes the agricultural sector shrink and the service sector expand, provided that the agricultural good and manufacturing good prices fall relative to the service sector good.

Closed Economy Equilibrium Analysis. Similarly to the two-sector model analyzed in Appendix A, the optimization problem of households in the three-sector model gives the 
following conditions in terms of the control variables $c_{1}, c_{2}$, and $c_{3}$, the state variable $k$, and the co-state variable $\lambda: c_{1}-\overline{c_{1}}=\frac{\omega_{1}}{\omega_{2}} q_{1}^{-\varepsilon} c_{2}, c_{3}+\overline{c_{3}}=\frac{\omega_{3}}{\omega_{2}} q_{3}^{-\varepsilon} c_{2}, \lambda c_{2}=\left(1+\frac{\omega_{1}}{\omega_{2}} q_{1}^{1-\varepsilon}+\frac{\omega_{3}}{\omega_{2}} q_{3}^{1-\varepsilon}\right)^{-1}, \frac{d \lambda}{d t}=$ $\lambda(\delta+\rho-R)$. These four equations together with the initial condition $k(0)=k_{0}$ and the transversality condition in equation (13) determine the solution to the representative household optimization problem.

Firms choose the amount of inputs they want to hire each period in order to maximize their static profits. At the optimum, they choose the amount of capital and labor in each sector so that their marginal products are equalized: $\frac{\partial y_{2}}{\partial k_{2}}=q_{1} \frac{\partial y_{1}}{\partial k_{1}}=q_{3} \frac{\partial y_{3}}{\partial k_{3}}=R$ and $\frac{\partial y_{2}}{\partial n_{2}}=$ $q_{1} \frac{\partial y_{1}}{\partial n_{1}}=q_{3} \frac{\partial y_{3}}{\partial n_{3}}=w$, with the production functions defined in Equations (39) and (5).

The market clearing conditions state, first, that the labor input allocated to each sector is equal to the labor supply, $n_{1}+n_{2}+n_{3}=1$, second, that the capital input allocated to each sector is equal to the total capital stock, $k_{1}+k_{2}+k_{3}=k$, which can be written as $\kappa_{1}+\kappa_{2}+\kappa_{3}=1$ by defining $\kappa_{j} \equiv \frac{k_{j}}{k}$. Moreover, in a closed economy, the domestic demand of each good is equal to its domestic supply $c_{1}=y_{1}, c_{2}+\frac{d k}{d t}+(\delta+\nu) k=y_{2}$, and $c_{3}=y_{3}$.

The closed economy equilibrium conditions can be summarized by the following system of eleven equations in the eleven unknowns $\left[k(t), \lambda(t), c_{1}(t), c_{2}(t), c_{3}(t), n_{1}(t), n_{3}(t), \kappa_{1}(t)\right.$, $\left.\kappa_{3}(t), q_{1}(t), q_{3}(t)\right]_{t \geq 0}$ :

$$
\begin{aligned}
\frac{d k}{d t} & =\left(\left(1-\kappa_{1}-\kappa_{3}\right) k\right)^{\alpha}\left(A_{2}\left(1-n_{1}-n_{3}\right)\right)^{1-\alpha}-(\delta+\nu) k-c_{2} \\
\frac{d \lambda}{d t} & =\lambda\left(\rho+\delta-\alpha((1-\kappa) k)^{\alpha}\left(A_{2}(1-n)\right)^{1-\alpha}\right) \\
c_{1}-\overline{c_{1}} & =\frac{\omega_{1}}{\omega_{2}} q_{1}^{-\varepsilon} c_{2} \\
c_{3}+\overline{c_{3}} & =\frac{\omega_{3}}{\omega_{2}} q_{3}^{-\varepsilon} c_{2} \\
\lambda_{2} & =\left(1+\frac{\omega_{1}}{\omega_{2}} q_{1}^{1-\varepsilon}+\frac{\omega_{3}}{\omega_{2}} q_{3}^{1-\varepsilon}\right)^{-1} \\
q_{1} & =\left(\frac{\alpha}{\eta}\right)^{\alpha}\left(\frac{1-\alpha}{\beta}\right)^{1-\alpha}\left(\kappa_{1} k\right)^{\alpha-\eta} n_{1}^{1-\alpha-\beta} A_{2}^{1-\alpha} A_{1}^{-\beta} N^{1-\eta-\beta} \\
q_{3} & =\left(\frac{A_{2}}{A_{3}}\right)^{1-\alpha} \\
\frac{1-n_{1}-n_{3}}{1-\kappa_{1}-\kappa_{3}} & =\frac{(1-\alpha)}{\alpha} \frac{\eta}{\beta} \frac{n_{1}}{\kappa_{1}} \\
\frac{1-n_{1}-n_{3}}{1-\kappa_{1}-\kappa_{3}} & =\frac{n_{3}}{\kappa_{3}} \\
c_{1} & =\left(\kappa_{1} k\right)^{\eta}\left(A_{1} n_{1}\right)^{\beta} N^{\eta+\beta-1} \\
c_{3} & =\left(\kappa_{3} k\right)^{\alpha}\left(A_{3} n_{3}\right)^{1-\alpha}
\end{aligned}
$$

together with the boundary conditions $k(0)=0$ and equation (13). 
Let's now define the variables $\widehat{c_{2}} \equiv \frac{c_{2}}{A_{2}}, \widehat{k} \equiv \frac{k}{A_{2}}, \widehat{\lambda} \equiv \lambda A_{2}$, and $z_{1} \equiv \frac{A_{2}^{\alpha-\eta} A_{2}^{1-\alpha} N^{1-\eta-\beta}}{A_{1}^{\beta}}$. From equations (45), (48), and (52), we get

$$
\frac{\omega_{1}}{\omega_{2}} q_{1}^{1-\varepsilon} \widehat{c_{2}}=\left(\frac{\alpha}{\eta}\right)^{\alpha}\left(\frac{1-\alpha}{\beta}\right)^{1-\alpha}\left(\kappa_{1} k\right)^{\alpha} n_{1}^{1-\alpha}-\left(\frac{\alpha}{\eta}\right)^{\alpha}\left(\frac{1-\alpha}{\beta}\right)^{1-\alpha}\left(\kappa_{1} k\right)^{\alpha-\eta} n_{1}^{1-\alpha-\beta} \overline{c_{1}} z_{1},
$$

where the last term converges to zero asymptotically under condition (42). Similarly, from equations (46), (49), and (53), we get

$$
\frac{\omega_{3}}{\omega_{2}} q_{3}^{1-\varepsilon} \widehat{c_{2}}=\left(\kappa_{3} k\right)^{\alpha} n_{3}^{1-\alpha}+\left(\frac{1}{A_{2}}\right)^{\alpha}\left(\frac{1}{A_{3}}\right)^{1-\alpha} \overline{c_{3}},
$$

where the last term converges to zero as long as $\gamma_{2}>0$ or $\gamma_{3}>0$. Taking the ratio of these two equations we find that $\frac{\omega_{1}}{\omega_{3}}\left(\frac{q_{1}}{q_{3}}\right)^{1-\varepsilon}$ converges asymptotically to $\frac{\left(\frac{\alpha}{\eta}\right)^{\alpha}\left(\frac{1-\alpha}{\beta}\right)^{1-\alpha}\left(\kappa_{1} k\right)^{\alpha} n_{1}^{1-\alpha}}{\left(\kappa_{3} k\right)^{\alpha} n_{3}^{1-\alpha}}$. One can show that the term $\frac{q_{1}}{q_{3}}$ also converges to zero if the condition in equation (42) holds. Hence, when $0<\varepsilon<1$ and given equation (50), the fraction of inputs allocated to the agricultural sector is zero in the asymptotic steady state:

$$
\kappa_{1}^{s s}=n_{1}^{s s}=0 .
$$

This, together with equation (51) gives that $n_{3}^{s s}=\kappa_{3}^{s s}$.

At the same time, assuming that $\gamma_{2}>\gamma_{3}, \lim _{t \rightarrow \infty} \frac{1}{q_{3}}=0$. Thus, equations (46), (49), and (53) imply that, whenever $0<\varepsilon<1$,

$$
{\widehat{c_{2}}}^{s s}=0 .
$$

In the steady state, $\frac{d \widehat{k}}{d t}=\frac{d \widehat{\lambda}}{d t}=0$. Hence, from equation (44),

$$
\widehat{k}^{s s}=\left(\frac{\alpha}{\delta+\rho+\gamma_{2}}\right)^{\frac{1}{1-\alpha}}
$$

and, from equation (45) together with ${\widehat{c_{2}}}^{s s}=0$,

$$
n_{3}^{s s}=1-\left(\delta+\nu+\gamma_{2}\right)\left(\widehat{k}^{s s}\right)^{1-\alpha} .
$$

Finally, from equations (46) and (47),

$$
\widehat{\lambda}\left(\left(\kappa_{3} k\right)^{\alpha} n_{3}^{1-\alpha}+\left(\frac{1}{A_{2}}\right)^{\alpha}\left(\frac{1}{A_{3}}\right)^{1-\alpha}+\overline{c_{3}}\right)=\frac{1}{1+\frac{\omega_{2}}{\omega_{3}}\left(\frac{1}{q_{3}}\right)^{1-\varepsilon}+\frac{\omega_{1}}{\omega_{3}}\left(\frac{q_{1}}{q_{3}}\right)^{1-\varepsilon}} .
$$


Thus, under equation (42) and given $0<\varepsilon<1$ plus $\gamma_{2}>0$ or $\gamma_{3}>0$, we obtain that

$$
\widehat{\lambda}^{s s}\left(\widehat{k}^{s s}\right)^{\alpha} n_{3}^{s s}=1 .
$$

\section{C.2.3 Small Open Economy Competitive Equilibrium}

The small open economy equilibrium is almost identical to the closed economy one except for the fact that the agricultural and the manufacturing goods are tradable (with $x_{1}$ and $x_{2}$ denoting agricultural and nonagricultural net exports respectively) as well as the fact that the relative price, $q_{1}$, is now exogenous to the country (since it is set in the international markets). Formally, a competitive equilibrium for the small open economy, given the initial capital stock $k_{0}$ and the exogenous variables $\left[A_{1}(t), A_{2}(t), A_{3}(t), q_{1}(t), N(t)\right]_{t \geq 0}$, are a set of prices $\left[w(t), R(t), q_{2}(t), p(t)\right]_{t \geq 0}$ and quantities $\left[y_{1}(t), y_{2}(t), y_{3}(t), c_{1}(t), c_{2}(t), c_{3}(t)\right.$, $\left.x_{1}(t), x_{2}(t), n_{1}(t), n_{2}(t), n_{3}(t), k_{1}(t), k_{2}(t), k_{3}(t), k(t)\right]_{t \geq 0}$, satisfying the consumer optimization conditions, the firm optimization conditions and the market clearing conditions. In this case, the market clearing conditions state that the amount of inputs supplied domestically is equal to the amount demanded domestically, and that the domestic demand of final goods plus net exports (in the case of sectors 1 and 2) are equal to the domestic supply. International trade is assumed to be balanced at all periods, which implies that there is not international lending or borrowing.

In terms of the long-run equilibrium, in a context where the international price of the agricultural good decreases over time, the economy converges to an asymptotic steady state where the fraction of inputs allocated to the agricultural sector is zero, provided that the following condition is satisfied:

$$
(1-\eta) \gamma_{2}+(1-\eta-\beta) \nu-\beta \gamma_{1}-\gamma_{q}>0
$$

where $\gamma_{q} \equiv \frac{d q}{d t}$. In words, equation (54) states that the rate at which the international price of the agricultural good decreases is faster than the rate that would prevail in a closed economy context asymptotically.

Along the transition path, all goods will be produced unless the economy specializes imports all its manufacturing good because its international relative prices is low enough. It is that it is never optimal to specialize in nonagriculture because land is not productive in that sector. The actual fraction of productive inputs allocated to the agricultural sector at each point in time depends on the relation between the domestic and the international price of the agricultural good. Countries with low agricultural productivity or low land en- 
dowment will tend to import agricultural good and, hence, their agricultural sector will be smaller under trade than under autarky. Over time, assuming that equation (54) is satisfied, the economy will keep reallocating its inputs away from agriculture and, thus, structural transformation will take place.

Small Open Economy Equilibrium Analysis. Mathematically, the only difference in the small open economy equilibrium is the good market clearing conditions. In sectors 1 and 2 , the domestic demand of final goods plus net exports are equal to the domestic supply, while sector 3 is non-tradable: $c_{1}+x_{1}=y_{1}, c_{2}+x_{2}+\frac{d k}{d t}+(\delta+\nu) k=y_{2}$, and $c_{3}=y_{3}$. Since trade is assumed to be balanced at all periods, the value of exports is equal to the value of imports $q x_{1}+x_{2}=0$.

The small open economy equilibrium conditions can be summarized by the following system of eleven equations in the eleven unknowns $\left[k(t), \lambda(t), c_{1}(t), c_{2}(t), c_{3}(t), n_{1}(t), n_{3}(t)\right.$, $\left.\kappa_{1}(t), \kappa_{3}(t), q_{3}(t), x_{2}(t)\right]_{t \geq 0}$ :

$$
\begin{aligned}
\frac{d k}{d t} & =\left(\left(1-\kappa_{1}-\kappa_{3}\right) k\right)^{\alpha}\left(A_{2}\left(1-n_{1}-n_{3}\right)\right)^{1-\alpha}-(\delta+\nu) k-x_{2}-c_{2} \\
\frac{d \lambda}{d t} & =\lambda\left(\rho+\delta-\alpha((1-\kappa) k)^{\alpha}\left(A_{2}(1-n)\right)^{1-\alpha}\right) \\
c_{1}-\overline{c_{1}} & =\frac{\omega_{1}}{\omega_{2}} q_{1}^{-\varepsilon} c_{2} \\
c_{3}+\overline{c_{3}} & =\frac{\omega_{3}}{\omega_{2}} q_{3}^{-\varepsilon} c_{2} \\
\lambda c_{2} & =\left(1+\frac{\omega_{1}}{\omega_{2}} q_{1}^{1-\varepsilon}+\frac{\omega_{3}}{\omega_{2}} q_{3}^{1-\varepsilon}\right)^{-1} \\
q_{1} & =\left(\frac{\alpha}{\eta}\right)^{\alpha}\left(\frac{1-\alpha}{\beta}\right)^{1-\alpha}\left(\kappa_{1} k\right)^{\alpha-\eta} n_{1}^{1-\alpha-\beta} A_{2}^{1-\alpha} A_{1}^{-\beta} N^{1-\eta-\beta} \\
q_{3} & =\left(\frac{A_{2}}{A_{3}}\right)^{1-\alpha} \\
\frac{1-n_{1}-n_{3}}{1-\kappa_{1}-\kappa_{3}} & =\frac{(1-\alpha)}{\alpha} \frac{\eta}{\beta} \frac{n_{1}}{\kappa_{1}} \\
\frac{1-n_{1}-n_{3}}{1-\kappa_{1}-\kappa_{3}} & =\frac{n_{3}}{\kappa_{3}} \\
c_{1}+\frac{x_{2}}{q_{1}}= & \left(\kappa_{1} k\right)^{\eta}\left(A_{1} n_{1}\right)^{\beta} N^{\eta+\beta-1} \\
c_{3} & =\left(\kappa_{3} k\right)^{\alpha}\left(A_{3} n_{3}\right)^{1-\alpha},
\end{aligned}
$$

together with the boundary conditions $k(0)=0$ and transversality condition in equation (13).

Let's now define the variables $\widehat{k} \equiv \frac{k}{A_{2}}, \widehat{\lambda} \equiv \lambda A_{2}, \widehat{c_{2}} \equiv \frac{c_{2}}{A_{2}}, \widehat{x_{2}} \equiv \frac{x_{2}}{A_{2}}$, and $\zeta \equiv \frac{q_{1}}{A_{2}^{1-\eta} A_{1}^{-\beta} N^{1-\eta-\beta}}$. 
From equations (60) and (62), we get that

$$
\zeta=\left(\frac{\alpha}{\eta}\right)^{\eta}\left(\frac{1-\alpha}{\beta}\right)^{1-\eta} \widehat{k}^{\alpha-\eta}\left(\frac{1-\kappa_{1}-\kappa_{3}}{1-n_{1}-n_{3}}\right)^{\alpha-\eta} n_{1}^{1-\eta-\beta}
$$

Hence, given that $\lim _{t \rightarrow \infty} \zeta=0$ under condition $(54), \kappa_{1}^{s s}=n_{1}^{s s}=0$. This, together with equation (51), gives $n_{3}^{s s}=\kappa_{3}^{s s}$.

As in the closed-economy case, from equations (58), (61), and (65), together with $\gamma_{2}>$ $\gamma_{3}>0$, we conclude that ${\widehat{c_{2}}}^{s s}=0$. Similarly, from equations (57) and (61), we conclude that, equations (42) and (54) together with $0<\varepsilon<1$ are sufficient conditions to give ${\widehat{x_{2}}}^{s s}=0$.

In the steady state, $\frac{d \widehat{k}}{d t}=\frac{d \widehat{\lambda}}{d t}=\frac{d \widehat{c_{2}}}{d t}=0$. Hence, given these results and following the same steps as in the closed economy steady-state analysis, we obtain

$$
\begin{gathered}
n_{3}^{s s}=1-\left(\delta+\nu+\gamma_{2}\right) \widehat{k}^{s s}, \\
\widehat{k}^{s s}=\left(\frac{\alpha}{\delta+\rho+\gamma_{2}}\right)^{\frac{1}{1-\alpha}}, \\
\widehat{\lambda}^{s s}\left(\widehat{k}^{s s}\right)^{\alpha} n_{3}^{s s}=1 .
\end{gathered}
$$

The small open economy steady state, hence, is exactly the same the closed economy one.

\section{C.2.4 Simulations and Main Results of the Three-Sector model}

To simulate the models presented in the previous section, one must first specify the exogenous variables path as well as the parameter values. In terms of exogenous variables, the difference with respect to the two-sector model is that there is a TFP for manufactures and another one for services, while the agricultural price is now relative to the manufactures price. In South Korea, the manufacturing sector data corresponds to the industries Manufacturing, Construction, Mining and quarrying, Electricity, Gas and Water Supply, while services is the rest of the nonagricultural sector. Following the procedure described in Appendix B, I obtain an average growth rate during the sample period of $6.9 \%$ for the manufacturing sector and $3.1 \%$ for the service sector, and I use 5.7\% and $1.91 \%$ for future values (which are computed assuming that the overall employment-to-population ratio will stop growing in 10 years). In Great Britain, the manufacturing sector corresponds to Manufacture, Mining, and Building, , while services is also the rest of the nonagricultural sector. The estimated TFP growth rates for the 19th century are 1.91\% in the manufacturing sector and $1.64 \%$ in the service sector, with future values of $1.9 \%$ and $1.55 \%$ respectively. 
Figure 8: Three-sector model simulations
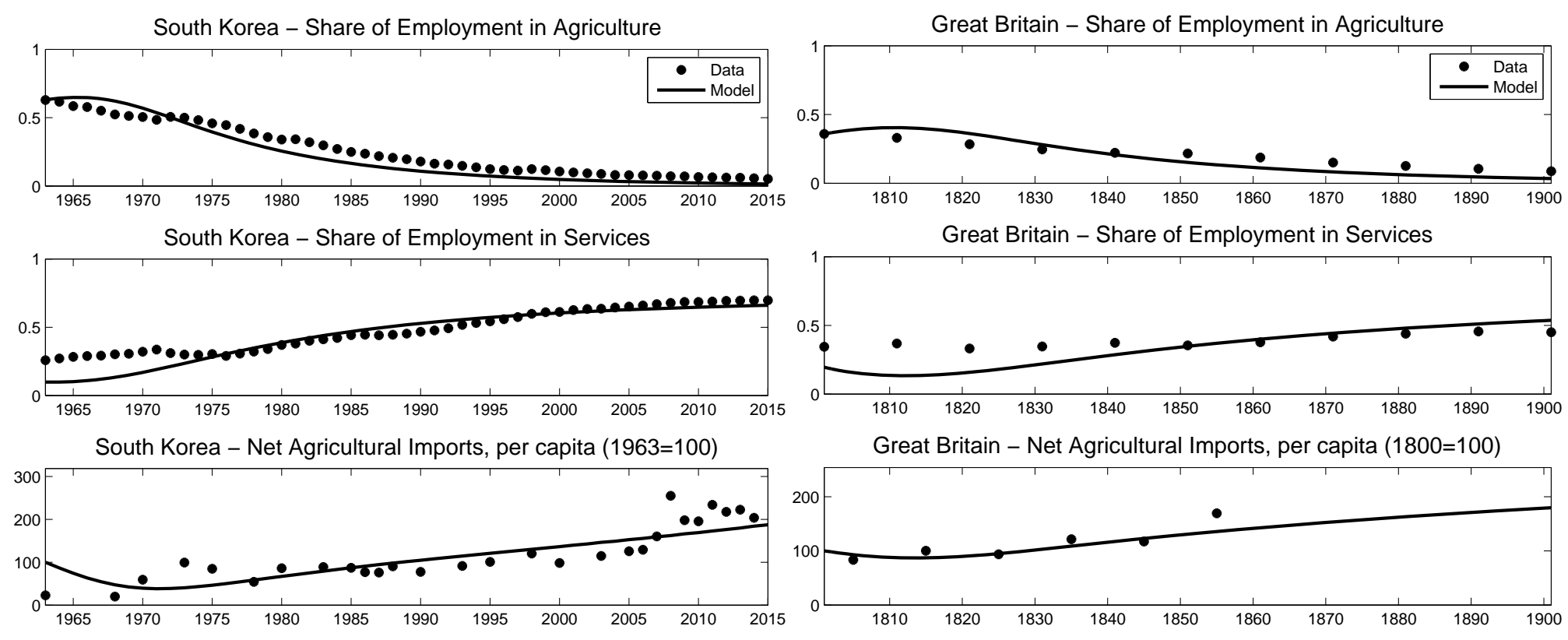

The agricultural relative price is now computed as the agricultural GDP deflator over the manufacturing GDP deflator, giving an average growth rate of $-0.4 \%$ in South Korea and $-0.04 \%$ in Great Britain. In South Korea, there is data on nominal and real GDP by sector, so the GDP deflators can be directly computed as the ratio between the two. In Great Britain, on the other hand, I first construct the agriculture real GDP dividing the agriculture nominal GDP by the Rousseaux price index for agriculture from Mitchell (1962), the manufacturing real GDP dividing the manufacturing nominal GDP by the Rousseaux price index for industrial products from Mitchell (1962), and the service real GDP substracting the agriculture and manufacturing real GDP from the aggregate real GDP.

With respect to the parameter values, $c_{1}$ is now $99.6 \%$ of the initial agricultural consumption in South Korea and $98.9 \%$ in Great Britain. The preference parameter $\omega_{3}$ takes a value 10 , while $\overline{c_{3}}$ is equal to $55 \%$ of the total services consumption in South Korea and $61.3 \%$ in Great Britain. The rest of the parameter take the values described in Table 1.

The numerical predictions of the three-sector model are presented in Figure 8 . It shows that in both cases the model is able to fit the data quite well, with the exception of the service employment share in the initial years.

To evaluate the importance of international trade, these simulations are compared to the ones under alternative scenarios. As before, the results under the open economy model presented in Appendix C.2.3 are compared to the results under the closed-economy model presented in Appendix C.2.2, both for South Korea and Great Britain. Additionally, for South Korea, I compare the open-economy results showed in Figure 8 with a free-trade counterfactual where the agriculture protectionist policies are removed. This free trade 
counterfactual for South Korea is computed using the 1975 agricultural sector tariff equivalent rate estimated in Diao et al. (2002) (which is equal to 65\%), together with the growth rate of the agricultural price relative to the manufacturing price in the United States for the period 1963-2015 (which is equal to -2.6\%).

In the case of South Korea, I obtain that relative to the autarky counterfactual, the capital stock has been $4.4 \%$ higher on average during the last 50 years, the agricultural price has been $15 \%$ lower, the agricultural employment share $32 \%$ lower, the service employment share $1.9 \%$ higher, while the consumption volumes have been $0.06 \%$ higher for agriculture, $1.16 \%$ higher for manufactures, and $1.43 \%$ higher for services. Under free trade, I find that relative to the autarky counterfactual, the capital stock would have been $17.6 \%$ higher on average during the last 50 years, the agricultural price $60 \%$ lower, the agricultural employment $85 \%$ lower, the service employment $21 \%$ higher, while the consumption volumes would have been $0.5 \%$ higher for agriculture, $14.5 \%$ higher for manufactures, and $17.6 \%$ higher for services.

Finally, in the case of Great Britain, I find that relative to the autarky counterfactual, the capital stock was 30\% higher on average during the 19th century, the agricultural price was $40 \%$ lower, the agricultural employment $70 \%$ lower, the service employment $35 \%$ higher, while the consumption volumes where $1 \%$ higher for agriculture, $28 \%$ higher for manufactures, and 34\% higher for services. 